\title{
Time Scales and Mechanisms for the Tropical Pacific Response to Global Warming: A Tug of War between the Ocean Thermostat and Weaker Walker
}

\author{
ULLA K. HEEDE \\ Department of Earth and Planetary Sciences, Yale University, New Haven, Connecticut \\ AleXey V. Fedorov \\ Department of Earth and Planetary Sciences, Yale University, New Haven, Connecticut, \\ and LOCEAN/IPSL, Sorbonne University, Paris, France \\ NATALIE J. BURLS \\ Department of Atmospheric, Oceanic and Earth Sciences, George Mason University, Fairfax, Virginia
}

(Manuscript received 16 September 2019, in final form 29 March 2020)

\begin{abstract}
Different oceanic and atmospheric mechanisms have been proposed to describe the response of the tropical Pacific to global warming, yet large uncertainties persist on their relative importance and potential interaction. Here, we use idealized experiments forced with a wide range of both abrupt and gradual $\mathrm{CO}_{2}$ increases in a coupled climate model (CESM) together with a simplified box model to explore the interaction between, and time scales of, different mechanisms driving Walker circulation changes. We find a robust transient response to $\mathrm{CO}_{2}$ forcing across all simulations, lasting between 20 and 100 years, depending on how abruptly the system is perturbed. This initial response is characterized by the strengthening of the Indo-Pacific zonal SST gradient and a westward shift of the Walker cell. In contrast, the equilibrium response, emerging after 50-100 years, is characterized by a warmer cold tongue, reduced zonal winds, and a weaker Walker cell. The magnitude of the equilibrium response in the fully coupled model is set primarily by enhanced extratropical warming and weaker oceanic subtropical cells, reducing the supply of cold water to equatorial upwelling. In contrast, in the slab ocean simulations, the weakening of the Walker cell is more modest and driven by differential evaporative cooling along the equator. The "weaker Walker" mechanism implied by atmospheric energetics is also observed for the midtroposphere vertical velocity, but its surface manifestation is not robust. Correctly diagnosing the balance between these transient and equilibrium responses will improve understanding of ongoing and future climate change in the tropical Pacific.
\end{abstract}

\section{Introduction}

A key component of the tropical Pacific climate system is the Walker circulation, which maintains the zonal SST gradient and thermocline structure along the equator (Fig. 1) as part of the Bjerknes feedback (Bjerknes 1966). Changes to the Walker circulation can influence a range of important climatic phenomena, including ENSO (e.g., Fedorov and Philander 2000; Collins et al. 2010; DiNezio et al. 2012), tropical precipitation (Held and Soden 2006; Dayem et al. 2007; Chadwick et al. 2013), the ITCZ strength and position (Hu and Fedorov 2018), the Indian monsoon

Corresponding author: Ulla K. Heede, ulla.heede@yale.edu
(Krishnamurthy and Krishnamurthy 2014), and ocean heat uptake (England et al. 2014, and many others).

How the tropical Pacific may change in response to warming has been a topic of active debate for decades. Yet, due to the complex coupled nature of atmosphereocean interactions driving the zonal circulation in the region, much uncertainty persists concerning the future of the Walker circulation and the associated zonal SST gradient, as well as interpretation of current observations. While the majority of general circulation models (GCMs) participating in phase 5 of the Climate Model Intercomparison Project (CMIP5) project a weakening of the SST gradient (DiNezio et al. 2013; Kociuba and Power 2015; Plesca et al. 2018; Coats and Karnauskas 2017), some models project no change or strengthening 


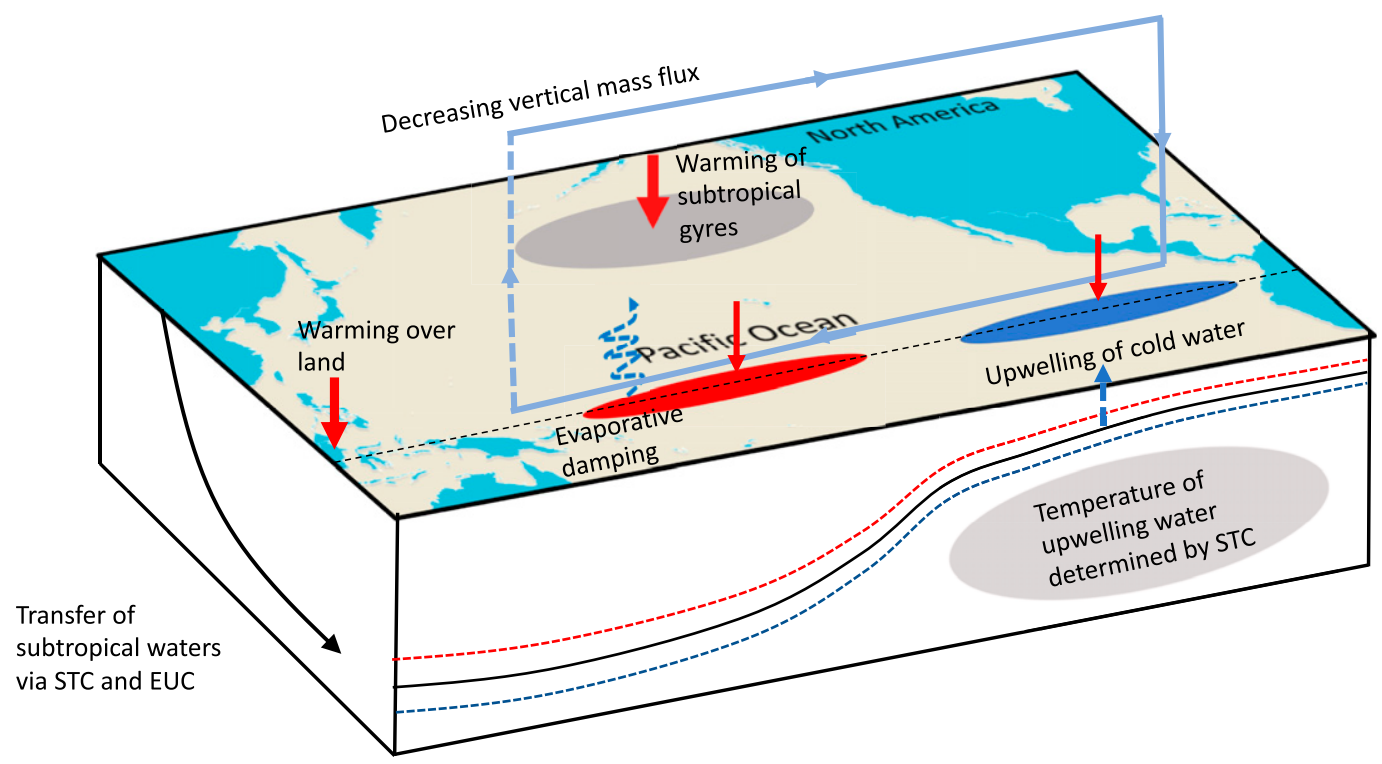

FIG. 1. Schematic overview of the ocean-atmosphere system in the tropical Pacific and relevant atmospheric and oceanic mechanisms (evaporative damping, decreasing vertical mass flux related to atmospheric energetics, the oceanic tunnel and ocean thermostat) that drive changes in the tropical SST gradients in response to greenhouse warming.

(e.g., Kohyama et al. 2017). Recent observations of the past several decades also show a strengthening of the zonal SLP and SST gradients, accompanied by an increase in zonal wind stress (Meng et al. 2012; Tokinaga et al. 2012; Ma and Zhou 2016) mirrored by an increase in meridional, cross-equatorial winds ( $\mathrm{Hu}$ and Fedorov 2018). These trends are not captured by historical simulations in CMIP5 (Kociuba and Power 2015), which generally show weaker SLP and SST gradients since preindustrial time; however, the robustness of the simulated trends has been questioned because of large intermodel spread (Plesca et al. 2018). The discrepancies between observations and model simulations have been linked to both model mean-state biases (e.g., Seager et al. 2019) and a lack of simulated interbasin warming trends. Sensitivity experiments confirm that enhanced warming in the Indian and Atlantic Oceans can drive some the observed wind stress changes in the Pacific (e.g., Zhang and Karnauskas 2017; McGregor et al. 2014; Zhang et al. 2019); however, such interbasin warming patterns are not well captured in historical CMIP simulations. In general, these factors cast doubt on whether current, state-of-the-art, climate models are able to give robust projections for the future of the equatorial Pacific, and call for a more in-depth understanding of the mechanisms that drive mean state changes to the Walker circulation, their time scales, and in particular how atmospheric and oceanic responses interact in the coupled system.
Generally, two types of mechanisms involving a dynamic ocean response to greenhouse gas (GHG) forcing, and resultant changes to the tropical SST gradient, have been proposed and investigated in the literature. One, typically named "the oceanic bridge" (or, more intuitively, "the oceanic tunnel") is related to tropical-extratropical oceanic links (Fig. 1). Specifically, a warming temperature signal from the extratropics can be transferred to the tropics via subduction in the subtropical gyre region, advection via the shallow subtropical cells (STCs), and upwelling in the eastern equatorial cold tongue (McCreary and Lu 1994; Gu and Philander 1997; Rodgers et al. 2003; Burls et al. 2017). Fedorov et al. (2015) find, based on paleo-evidence and equilibrated modeling experiments, a strong relationship between the zonal and meridional SST gradients in the Pacific, suggesting that the oceanic tunnel is a robust climatic feature with important control on the equatorial SST pattern on long time scales. In fact, Thomas and Fedorov (2017) estimate that extratropical and tropical signals become well correlated on time scales longer than 60 years.

Furthermore, in context of contemporary global warming, Liu (1998), Seager and Murtugudde (1997), and Burls and Fedorov (2014) have demonstrated, using simple box models and GCMs, that the steady-state zonal SST gradient in the tropics depends on the effective differential latitudinal heating and associated meridional SST gradients, suggesting that on multidecadal and centennial scales 
the oceanic tunnel is likely an important mechanism driving changes in the equatorial Pacific in response to global warming. In addition to enhanced extratropical warming, the reduction in the strength of the STCs caused by the weakening of surface winds could also act to warm the tropical Pacific as part of the oceanic tunnel response, due to reduced equatorial upwelling (Yamanaka et al. 2015). Thus, the complete oceanic tunnel should be understood as having both temperature and transport components.

The ocean thermostat is another dynamical ocean mechanism proposed, arguing that the zonal SST gradient will be enhanced in response to GHG warming (Clement et al. 1996). As warm surface waters pile up in the western equatorial Pacific, continual upwelling of cold water acts to strengthen the SST temperature difference between east and west, and hence establish a $\mathrm{La}$ Niña-like response to warming via the Bjerknes wind feedback (see Fig. 1). The ocean thermostat mechanism has been demonstrated using a box model (Liu and Huang 1997), the Zebiak-Cane model (Clement et al. 1996), and in a GCM (Luo et al. 2017). However, for most CMIP5 climate models, this type of response has not been detected as a dominant equilibrium response (DiNezio et al. 2009; Kociuba and Power 2015). While it may play a role in some models, whose responses differ from the CMIP5 mean (e.g., Kohyama et al. 2017), Coats and Karnauskas (2017) find that not all models simulating strengthening of the tropical SST gradient are consistent with the ocean thermostat proposed by Clement et al. (1996). More recently, Seager et al. (2019) proposed a modified ocean thermostat mechanism that includes an increase in winds due to a strong evaporative cooling effect in the trade wind belts, which in turn acts to increase zonal wind stress across the equatorial Pacific and enhance the ocean thermostat mechanism.

In parallel with the dynamical ocean or dynamical ocean-atmosphere mechanisms proposed, there has been a somewhat separate debate about how the tropical atmospheric overturning circulation, specifically the zonal Walker circulation, may respond to GHG forcing from a mainly atmospheric perspective. Broadly, two different mechanisms that may weaken the tropical zonal circulation in response to warming have been put forward. Knutson and Manabe (1995) focused on the weakening of the east-west SST gradient because of evaporative damping. Due to the exponential dependence of evaporative fluxes on SST stemming from the Clausius-Clapeyron relation, a larger proportion of increased energy from GHG forcing may be balanced by latent heat fluxes in the warm pool, relative to the cold tongue, leading to enhanced warming in the cold tongue relative to the warm pool, assuming constant wind stress and relative humidity. Merlis and Schneider (2011) show that in a cloud-free atmospheric model coupled to a mixed layer ocean (slab ocean), with fixed ocean energy flux divergence ( $Q$ flux), the weakening of the zonal SST gradient scales closely to that given by the Clausius-Clapeyron relation ( $\sim 7 \%$ per degree of warming) across a broad range of climates. In slab ocean simulations with a range of low cloud cover feedback strengths, Erfani and Burls (2019) show that the presence of clouds acts to amplify this thermodynamically driven weakening of the zonal SST gradient even in the absence of ocean coupling.

The second atmospheric mechanism focuses on changes to the atmospheric mass flux (or vertical velocity) and energy balance over the warm pool as put forward by Held and Soden (2006). Since radiative cooling in the upper troposphere increases at roughly $2 \%$ per degree warming, the only way that increases in latent heat release ( $7 \%$ per degree warming, consistent with the ClausiusClapeyron relation under constant relative humidity) can be in balance with weaker radiative cooling is by slowing down the vertical velocity of the circulation advecting water vapor upward. Vecchi and Soden (2007) found that vertical velocity over the Indo-Pacific decreased in future projections made by CMIP3 models, while Merlis and Schneider (2011) found a slowdown of vertical velocity of $5 \% \mathrm{~K}^{-1}$ in simulations with a cloud-free atmospheric model coupled to a slab ocean. Conducting experiments using prescribed wind stress within the ocean component of a GCM, Luo et al. (2015) have found, however, that the weakening of the tropical SST gradient can be reproduced, even in the absence of wind stress changes, highlighting that changes to the thermodynamic fluxes between the atmosphere and the ocean, alongside ocean dynamics, might be sufficient to drive a weakening of the SST gradient without the effect of surface winds associated with the weakening of the ascending branch of the Walker circulation.

While all these mechanisms have been shown to be able to operate in the tropical Pacific, at least to some degree, there is still no consensus about which mechanisms will ultimately dominate the response to contemporary global warming, an uncertainty that is also illustrated by the ongoing debates on the current trends of change in the region. This study aims to address this challenge by proposing a framework in which the above outlined atmospheric and oceanic mechanisms (summarized in Fig. 1) can be considered together, and their interactions and relative contributions studied. The ultimate motivation is to obtain a more robust understanding of current and future changes in the tropical Pacific. This framework is developed in two steps. First, a series of idealized $\mathrm{CO}_{2}$ forcing experiments, abrupt and more gradual, using both a slab 
ocean and fully coupled climate model, are carried out, in which the various responses can be clearly identified. Second, a simple box model, capturing key features of ocean-atmosphere interaction and tropical-extratropical coupling, is used. A series of box model experiments are performed, reproducing the main characteristics of the GCM simulation response, and thus allowing for an assessment of the role of the different proposed mechanisms in isolation and in combination with each other.

The remaining article is structured as follows: section 2 describes the GCM simulations used in the study and investigates the time scales of various types of responses identified in the GCM simulations, and their attribution to atmospheric and oceanic mechanisms. Section 3 describes the idealized box model, which is used to illustrate how the different mechanisms evident in the GCM simulations can be isolated and their interaction can be studied. Section 4 discusses and concludes the findings presented. A complementary study that compares and contrasts the response of the tropical Pacific across different GCMs will appear elsewhere.

\section{GCM simulations}

\section{a. Model setup}

We use a series of idealized, abrupt, and gradual $\mathrm{CO}_{2}$ increase experiments in order to investigate the interaction between oceanic and atmospheric responses under a range of different forcing scenarios. The experiments are performed using the T31 gx3v7 configuration of CESM (v. 1.0.4. and therefore essentially CCSM4 at the given resolution) with a nominal $\sim 3.75^{\circ}$ atmospheric resolution and an oceanic latitudinal resolution of about $3^{\circ}$ increasing to $0.5^{\circ}$ near the equator. This configuration, which is relatively coarse, allows us to perform a large number of ensemble simulations. Four abrupt forcing scenarios are used as a starting point to explore how the tropical Pacific responds to 2 , 4,8 , and $16 \mathrm{xCO}_{2}$ concentration relative to the preindustrial level. By abruptly forcing the system with large magnitudes of $\mathrm{CO}_{2}$, the response can be clearly separated from natural variability. The experiments are run for 400 years, and a five-member ensemble approach is used as an additional means to separate the forced response from natural variability, for instance associated with ENSO. The ensemble members have been created using the same method as in Kay et al. (2015), where each simulation is generated from one control experiment, but with an added temperature perturbation of magnitude $10^{-14} \mathrm{~K}$. All our experiments are initiated from the same start date and from the same baseline simulation (b.40) made available by the National
Center for Atmospheric Research (NCAR) with 1850 forcing that has been spun up for 507 years. Year zero in our simulations is the year at which $\mathrm{CO}_{2}$ is being added to all experiments, except the control, which is simply a continuation of the baseline experiment with added ensemble members.

To isolate the effects of the atmospheric mechanisms in the absence of a dynamical ocean, the model simulations are repeated using a slab ocean model (SOM) configuration with a prescribed ocean energy flux divergence into the mixed layer. This flux is computed from the fully coupled control simulation, and then used to force the slab ocean runs. In addition, a set of fully coupled ramp experiments are also carried out, in which $\mathrm{CO}_{2}$ concentration is increased linearly until it reaches the level of 1140 ppm (4 times preindustrial) and then kept constant. The goal of this set of experiments is to study the relative importance of different mechanisms, and how they may change in gradual versus abrupt forcing scenarios.

\section{b. The tropical Pacific response to $\mathrm{CO}_{2}$ forcing: Transient versus equilibrium response}

As expected, the tropical Pacific responds very quickly, within the first year, to the imposed abrupt $\mathrm{CO}_{2}$ increase, and continues to change over the next several centuries (Fig. 2). To highlight the temporal evolution of this trend, we compare the SST gradient between the Indo-west Pacific and central-east Pacific (see Table 1 for definitions), whereas the full spatial warming pattern is shown in Fig. 3 and described in more detail in section 2c. The temporal evolution of the response clearly shows two different stages: the initial (transient) and final (equilibrium), characterized by a strengthening, and then weakening of the Pacific Walker cell, respectively. Note that here we use the terms strengthening and weakening to describe the state of the system (i.e., stronger or weaker Walker cell relative to the control) rather than a trend (i.e., the rate of change) during this period. The SST and SLP gradients and integrated zonal wind stress (Figs. 2a-c) show a strengthening that lasts about 20-30 years (a stronger Walker cell), followed by a rapid weakening (a weaker Walker cell) that stabilizes after 100-200 years.

The spatial structure of the initial response in SST is qualitatively similar between different magnitude of $\mathrm{CO}_{2}$ increase; likewise, the structure of the final response also shows strong similarities for different forcing magnitudes (Fig. 3). However, in all experiments, there is a sharp difference between the structure of the transient and equilibrium responses in the central Pacific.

The initial response is characterized by less warming in the central equatorial Pacific, and in the trade wind belts, particularly in the Southern Hemisphere. Qualitatively, the spatial pattern of SST in the initial 

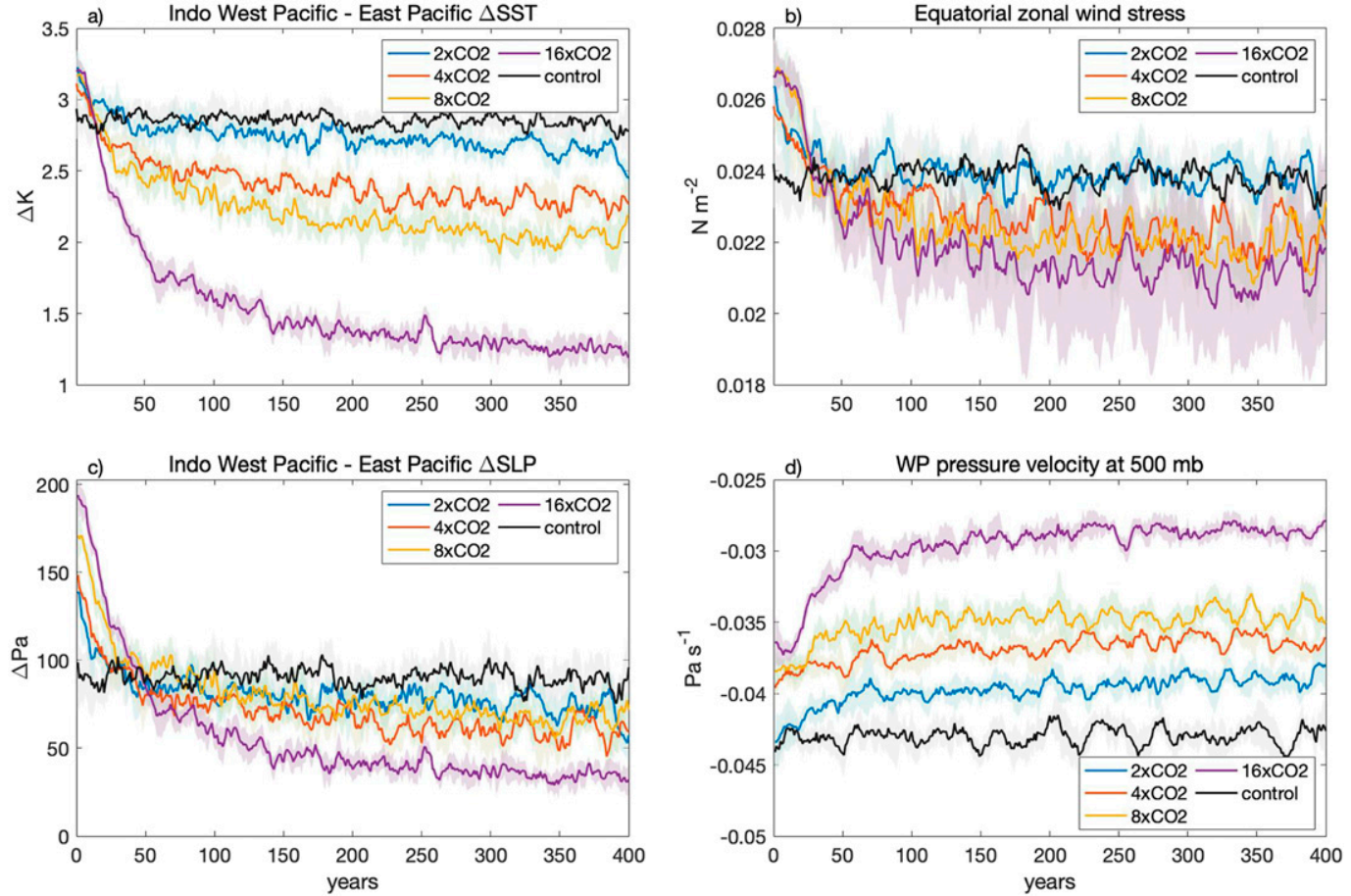

FIG. 2. Changes in key variables in the control and abrupt $\mathrm{CO}_{2}$ experiments: (a) SST difference between the Indowest Pacific and the central-east Pacific (see Table 1 for definitions), (b) zonal wind stress integrated over the equatorial tropical Pacific basin, (c) sea level pressure difference between the Indo-west Pacific and the central-east Pacific, and (d) pressure velocity over the Indo-west Pacific. The 10-yr running means averaged across five ensemble members are shown; shading indicates ensemble spread.

response resembles the negative phase of the inderdecadal Pacific oscillation (IPO; e.g., Dong and Dai 2015). Here, we emphasize the IPO rather than the Pacific decadal oscillation (PDO) traditionally defined within the Northern Hemisphere. In the negative IPO phase, the regions with reduced warming that extend from the midlatitude eastern parts of the Pacific basin toward the western tropical Pacific are indicative of the Pacific meridional mode (Chiang and Vimont 2004; Zhang et al. 2014) driven largely by the wind-evaporation-SST (WES) feedback (e.g., Xie and Philander 1994).

In contrast to the initial change, the equilibrium response shows a pronounced warming over the eastern equatorial Pacific, reminiscent of an eastern Pacific El Niño-like state. Figure 4 illustrates in further detail the spatial structure of the transient versus equilibrium equatorial response. Initially, the warm pool shifts toward the Indian Ocean, while the coldest part of the cold tongue shift westward as well. The equilibrium response, on the other hand, shows a marked weakening of the east-west tropical SST gradients.

The initial strengthening in the Walker cell (in terms of SST and SLP gradients and zonal winds) is evident in both the abrupt (Fig. 2) and gradual experiments (Fig. 5), yet for the ramp scenarios, the strengthening response evolves more slowly, and lasts up to 70-100 years before the tropical SST gradient becomes weaker than the control. Furthermore, the ramps forced with faster $\mathrm{CO}_{2}$ increase (ramps $2-4$, reaching $4 \mathrm{xCO}_{2}$ ) seem to have a stronger transient response, while the ramp forced with the slowest $\mathrm{CO}_{2}$ rise (ramp 1) shows a very muted transient response. Eventually, the ramp experiments seem to converge on the equilibrium response in the abrupt experiments.

\section{c. The transient response: A stronger Walker cell and the Indo-Pacific thermostat}

The initial response is characterized by an increase in easterly winds over the central and western Pacific, and

TABLE 1. Definitions of spatial metrics.

\begin{tabular}{lc}
\hline \hline \multicolumn{1}{c}{ Metric name } & Definition \\
\hline Indo-west Pacific & $80^{\circ}-130^{\circ} \mathrm{E}, 5^{\circ} \mathrm{S}-5^{\circ} \mathrm{N}$ \\
Central-east Pacific & $180^{\circ}-280^{\circ} \mathrm{E}, 5^{\circ} \mathrm{S}-5^{\circ} \mathrm{N}$ \\
West Pacific & $120^{\circ}-150^{\circ} \mathrm{E}, 5^{\circ} \mathrm{S}-5^{\circ} \mathrm{N}$ \\
East Pacific & $205^{\circ}-280^{\circ} \mathrm{E}, 5^{\circ} \mathrm{S}-5^{\circ} \mathrm{N}$ \\
Tropical Pacific & $130^{\circ}-280^{\circ} \mathrm{E}, 5^{\circ} \mathrm{S}-5^{\circ} \mathrm{N}$ \\
Southern Pacific & $200^{\circ}-280^{\circ} \mathrm{E}, 50^{\circ}-20^{\circ} \mathrm{S}$ \\
Northern Pacific & $160^{\circ}-240^{\circ} \mathrm{E}, 20^{\circ}-50^{\circ} \mathrm{N}$
\end{tabular}



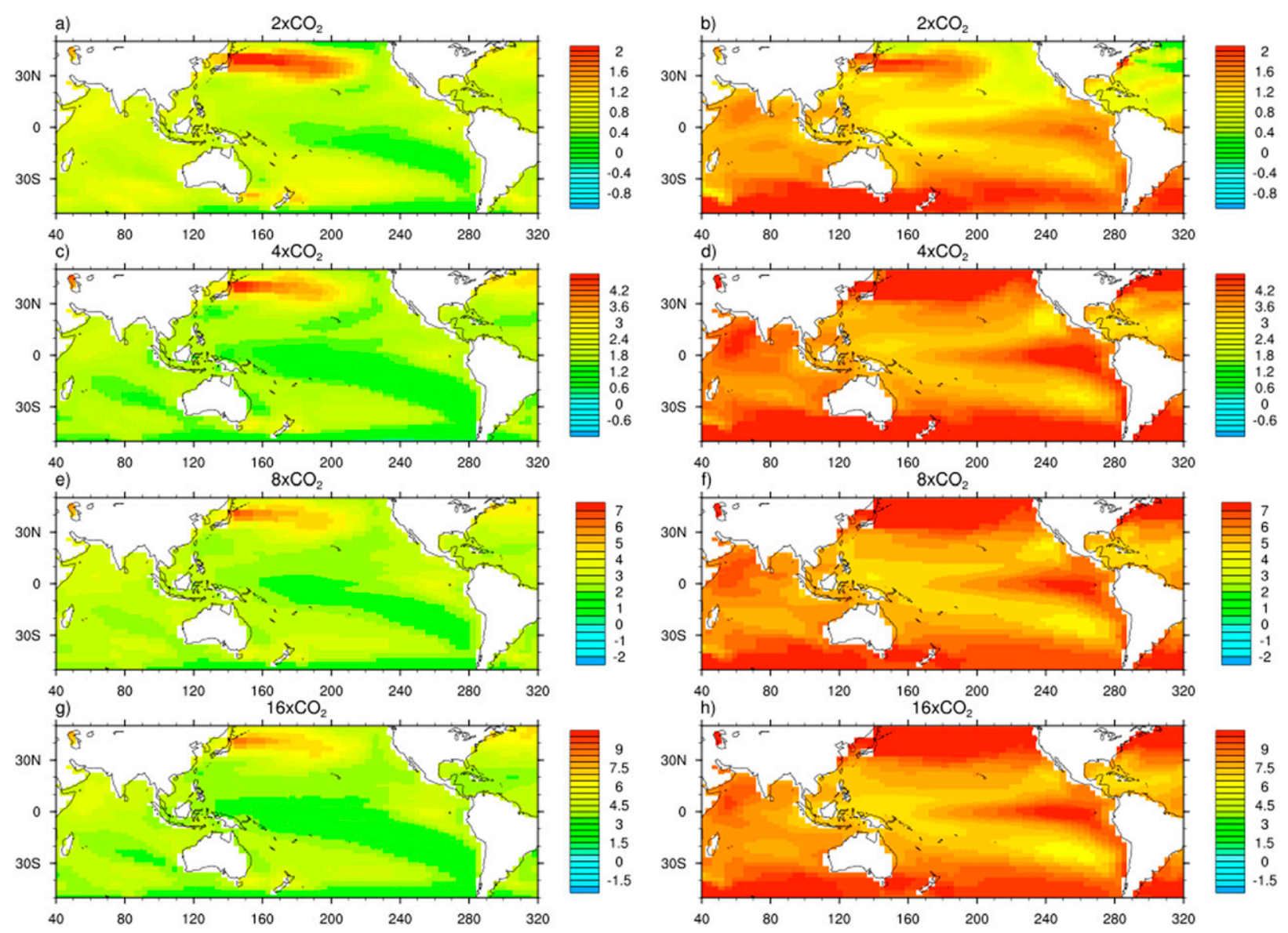

FIG. 3. Mean SST anomalies relative to the control $\left({ }^{\circ} \mathrm{C}\right)$ for the four abrupt $\mathrm{CO}_{2}$-rise experiments $(2,4,8$, and $16 \mathrm{xCO})$, showing averages for (a),(c),(e),(g) the first 10 years of each simulation and (b),(d),(f),(h) the last 100 years of each simulation. Note that the color bars are adjusted for each $\mathrm{CO}_{2}$ scenario. Five-member ensemble means are used.

an increase in vertical velocity and wind convergence over the Maritime Continent, which acts to shift the Walker circulation westward (Fig. 4; also see Fig. 10). In part, this westward shift is caused by a pronounced warming in the Indian Ocean, while the central and western Pacific warms less (Figs. 3 and 4). Enhanced Indian Ocean warming is a salient feature of climate change in the tropics observed over the past half-century or longer (e.g., Zhang et al. 2019). A simple explanation is that zonal winds over the equatorial Indian Ocean are weak, so that the Indian Ocean mixed layer temperature has to increase to balance the imposed forcing. Conversely, in the Pacific, the radiative forcing can be balanced by changes in upwelling, among other mechanisms, which can effectively reduce or even reverse any SST increase there. The enhanced Indian Ocean warming leads to a Gill-type response involving stationary Rossby and Kelvin waves (Matsuno 1966; Gill 1980). The latter wave strengthens zonal winds over the Pacific, which further reduces warming over the central and western Pacific by increasing upwelling as well as evaporative cooling ( $\mathrm{Hu}$ and Fedorov 2019). This type of westward wind response is also present in our slab ocean simulations (Figs. 4c,f), suggesting a clear role for the atmosphere in setting the spatial pattern of the initial response. The most noticeable difference between the fully coupled and slab ocean initial responses, however, is the magnitude of wind change. While the Walker circulation shifts westward in both cases, only the fully coupled simulations exhibit a strengthening of the winds in the central Pacific (Fig. 4d). This points to the role of the dynamical ocean in amplifying the initial response, creating a transient Indo-Pacific thermostat response to warming.

This Indo-Pacific thermostat is, however, somewhat different from the original idea of Clement et al. (1996). In fact, the main difference between the transient and equilibrium responses in our simulations lies not in the eastmost equatorial Pacific $\left(240^{\circ}-280^{\circ} \mathrm{E}\right)$, which warms immediately after imposed forcing, but 
Fully-coupled simulation: initial response
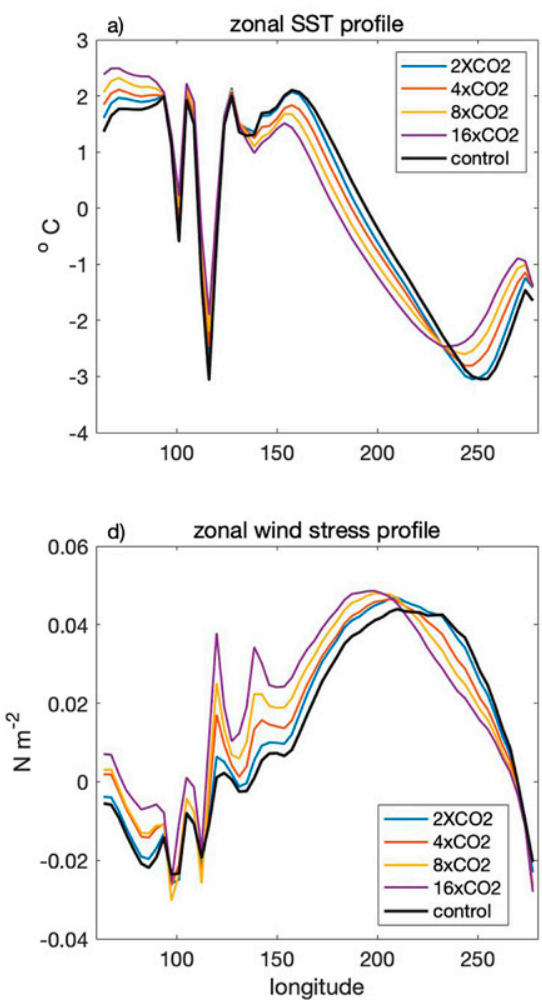

Fully-coupled simulation: equillibrium response
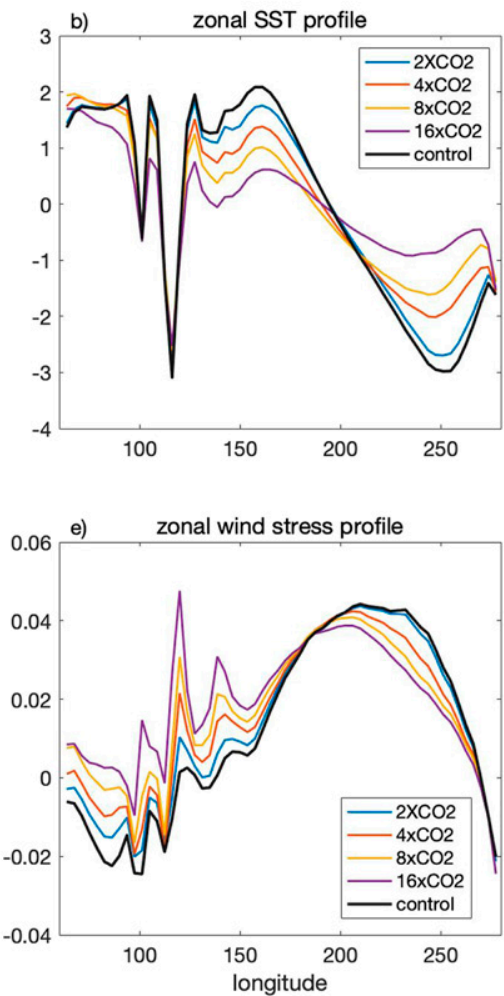

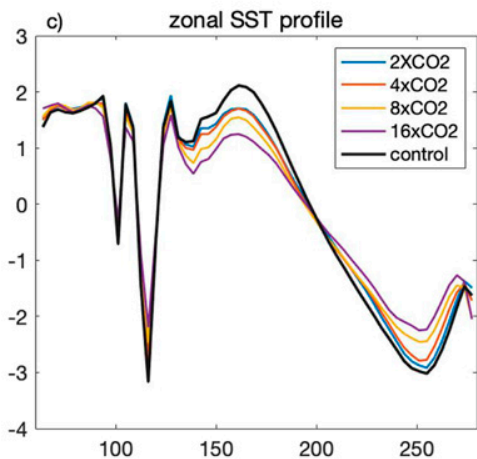

SOM simulation

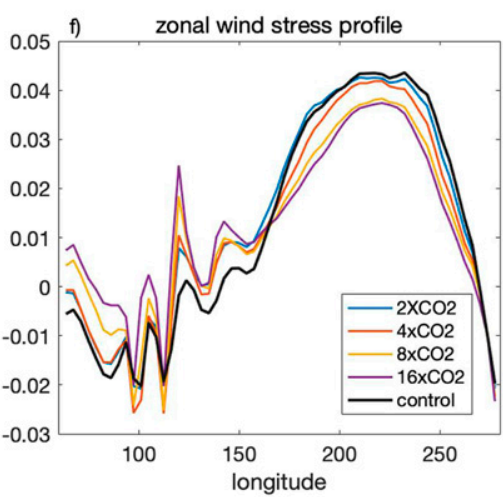

FIG. 4. (a)-(c) Equatorial surface temperature with the zonal mean substracted, and (d)-(f) zonal wind stress along the equator for each $\mathrm{CO}_{2}$ scenario. (left) The fully coupled model initial response (first 10 years) and (center) equilibrium (last 100 years) response to $\mathrm{CO}_{2}$. (right) The slab ocean response (first 10 years). Both variables are averaged between $5^{\circ} \mathrm{S}$ and $5^{\circ} \mathrm{N}$. Ensemble means are used for the fully coupled simulations.

in the central-east Pacific $\left(180^{\circ}-240^{\circ} \mathrm{E}\right)$, which initially experiences a lack of warming and stronger winds, moderating the induced warming in the whole Pacific equatorial band (Fig. 3). Only after 30 years does this central-east Pacific region start to experience weaker winds and enhanced warming as evident in Figs. 2 and 4 , thus it is the key region in the transition between the initial and equilibrium responses.

The initial warming of the far east Pacific is another important part of the transient response, and can be attributed in part to the strong warming over South America, resulting in westerly wind anomalies and a deepening of the thermocline in the eastmost equatorial Pacific. Meanwhile, the warming of the Maritime Continent and resultant low pressure anomalies strengthen zonal winds in the western Pacific and shoal the central Pacific thermocline, in turn further amplified by the Bjerknes feedback. The sum of these changes could be interpreted as a westward shift of the Walker circulation. In addition, the hemispherically asymmetric warming patterns in the trade wind belts, possibly linked to increased evaporative cooling (e.g., Seager et al. 2019), may also contribute to the westward shifting thermostat mechanism. These ideas will be investigated in a follow-up study.

While the initial response is similar in magnitude between the fully coupled and slab ocean simulations, the slab ocean simulations show a markedly muted response in the zonal SST gradient, compared with the fully coupled equilibrium response (Fig. 6). If one considers only the zonal SST gradient over the Pacific Ocean (ignoring changes over the Maritime Continent), the weakening observed in the slab ocean simulations is in reasonable agreement with what one would expect from the evaporative cooling argument: a larger proportion of warming in the warm pool can be balanced by latent heat fluxes, relative to the cold tongue. This is due to the exponential dependence of evaporative fluxes on SST set by the Clausius-Clapeyron relation, which controls saturation specific humidity at the ocean surface. In contrast, the fully coupled simulations show a much stronger SST gradient response to tropical warming. This result provides a clear indication of the role of the dynamical ocean in setting the magnitude of the 

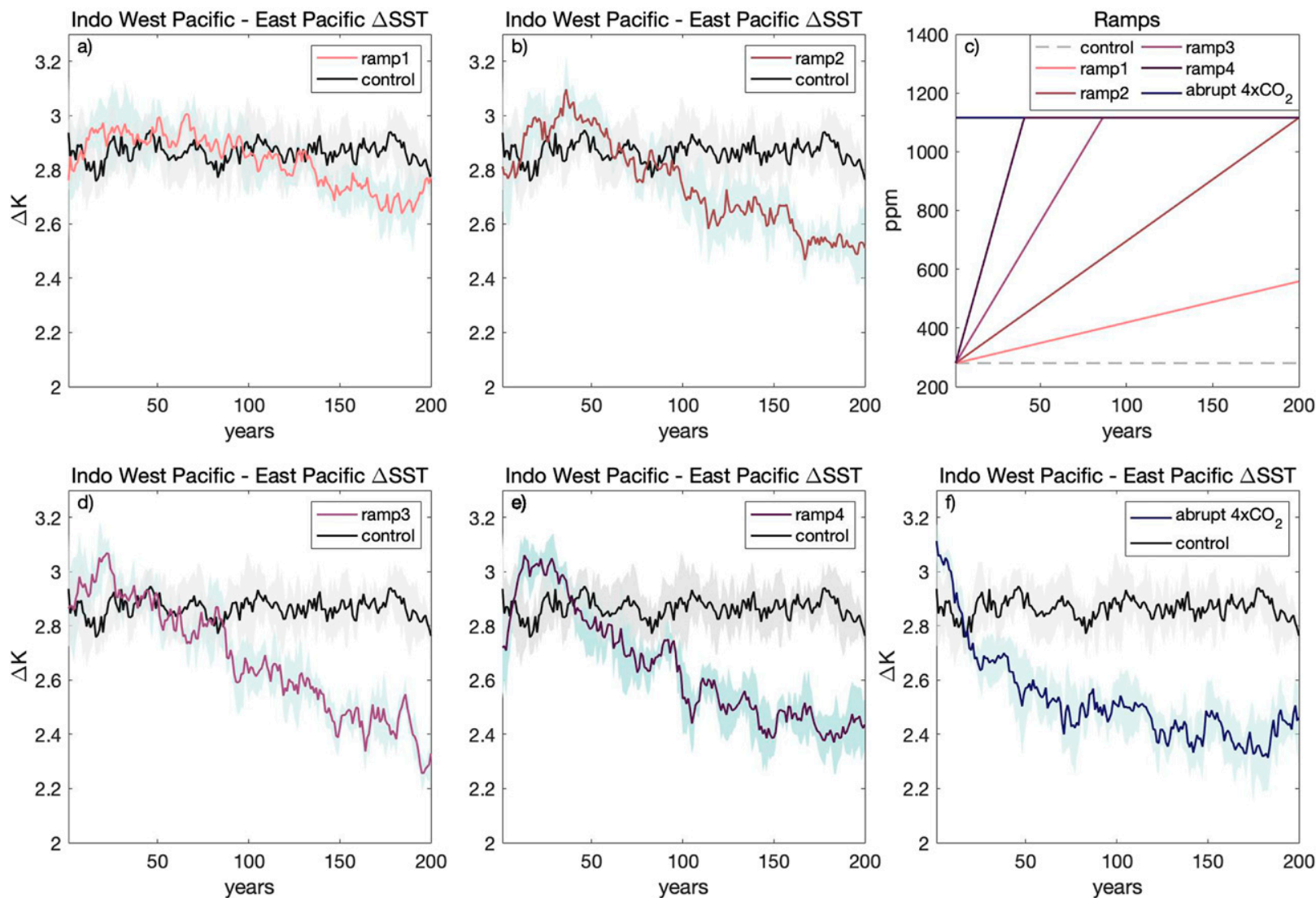

FIG. 5. SST difference between the Indo-west Pacific and the central-east Pacific for (a),(b),(d),(e) four different ramp experiments and (f) the abrupt $4 \mathrm{xCO}_{2}$ experiment; 10-yr running means averaged across five ensemble members are shown; shading indicates ensemble spread. (c) $\mathrm{CO}_{2}$ changes in the ramp experiments. Over the first 200 years ramps $2-4$ reach $1120 \mathrm{ppm}\left(4 \mathrm{xCO}_{2}\right.$ relative to the preindustrial level) and then maintain constant $\mathrm{CO}_{2}$; ramp 1 only reaches $2 \mathrm{xCO}_{2}$.

equilibrium SST response to $\mathrm{CO}_{2}$ forcing in the fully coupled simulations.

\section{d. The equilibrium response: The weaker Walker cell and the role of the oceanic tunnel}

Even though the initial dynamical/thermodynamical system response leads to a transient strengthening of zonal winds in the coupled model simulations, as well as increased zonal SST and SLP gradients across the equatorial Indo-Pacific, the role of the ocean appears to reverse after 20-30 years (in the abrupt simulations), driving a marked weakening of the zonal Pacific SST gradient on longer time scales. This suggests a shift from an ocean thermostat-type response to an ocean tunnel type response, with the ocean tunnel type response operating on time scales longer than 30-20 years (70 years or longer for the ramp experiments; see Fig. 5).

Generally, our GCM simulations indicate a strong role for the oceanic tunnel and meridional coupling in setting both the time scale and the magnitude of the equilibrium response. All simulations show enhanced extratropical warming, relative to the tropics (Fig. 7) where the extratropical region is defined roughly as an average between $20^{\circ}$ and $50^{\circ} \mathrm{N}$ and between $20^{\circ}$ and $50^{\circ} \mathrm{S}$ (see Table 1). The difference in warming between the tropics and extratropics tends to increase with time, except for the $2 \mathrm{xCO}_{2}$ simulation, where the enhanced extratropical warming in only observed during the first 100 years. Note that the $2 \mathrm{xCO}_{2}$ simulation also shows the smallest zonal SST gradient weakening in the equilibrium response. After the first 50-100 years, all simulations appear to develop high correlations between zonal and meridional temperature gradients (Fig. 8), suggesting that the rate of extratropical warming relative to tropical warming may have an important control on the equilibrium response of the tropical zonal temperature gradient (note that here only the Pacific east-west gradient as defined in Table 1 is considered, and changes over the Maritime Continent and the Indian Ocean are excluded as those areas are not directly impacted by the ocean 

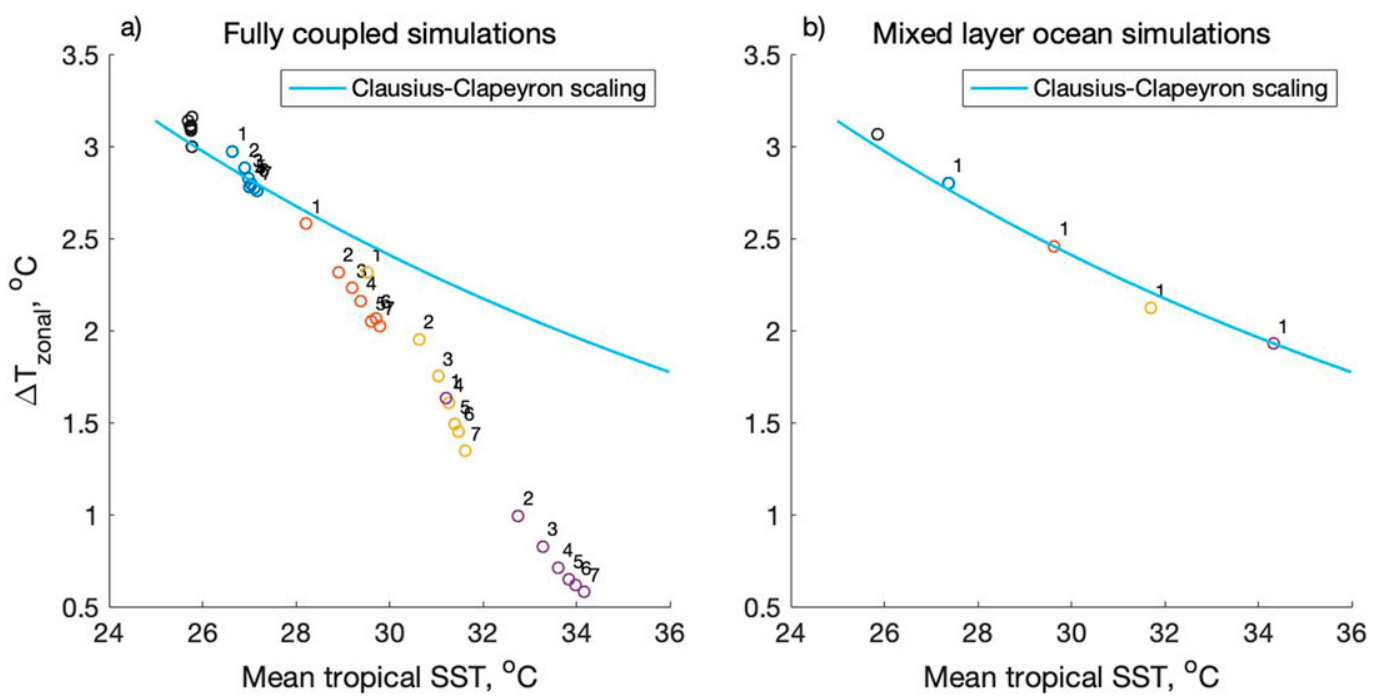

FIG. 6. Zonal SST gradient plotted against mean tropical Pacific SST $\left({ }^{\circ} \mathrm{C}\right)$ in the abrupt $\mathrm{CO}_{2}$ experiments. Each dot represents a 50-yr average of the SST difference between the west Pacific and east Pacific (see Table 1 for definitions) for (a) fully coupled and (b) slab ocean simulations. Number 1 indicates an average for years 1-50, number 2 for years 51-100, etc. Each $\mathrm{CO}_{2}$ scenario is plotted in a different color. Black = control simulation, blue = $2 \mathrm{xCO}_{2}$, red $=4 \mathrm{xCO}_{2}$, yellow $=8 \mathrm{xCO}_{2}$, and purple $=16 \mathrm{xCO}_{2}$. The blue line represents the theoretical reduction in the Pacific SST gradient of roughly $7 \%$ per degree of warming, assuming that evaporative damping is the only active mechanism, and the Clausius-Clapeyron relation controls saturation specific humidity at the surface.

tunnel mechanism). In addition to the enhanced extratropical warming, the slowdown of the Pacific wind-driven shallow overturning cells, also called the subtropical cells (STCs; Fig. 9), that supply cold water to equatorial upwelling in the eastern and central equatorial Pacific also contribute to the weakening of the zonal SST gradient. There appears to be some asymmetry in STC changes (Fig. 9) and extratropical warming (Fig. 7), with the Northern Hemisphere warming more than the Southern Hemisphere for all scenarios except $2 \mathrm{xCO}_{2}$. Likewise, the STC weakens in the Northern Hemisphere but strengthens (slightly) in the Southern Hemisphere.

These interhemispheric differences may be linked to asymmetry in the mean state winds and SST, which in turn can alter the balance between positive and negative latent heat flux feedbacks to the imposed forcing (Zhao and Fedorov 2020). Hemispheric asymmetry in the response of subtropical warming or STC strength, if pronounced, could have the effect of reducing or cancelling some contribution of the ocean tunnel driving the tropical SST response, which will be investigated in a follow-up study.

\section{e. The Walker cell weakening implied by energy and mass balance constraints}

Simple considerations of Held and Soden (2006), based on atmospheric energy and mass balance, suggest that the atmospheric tropical circulation should weaken when surface temperature rises. Their argument is commonly applied to the atmospheric vertical mass flux over the warm pool. Is there any evidence of their mechanism working in our simulations? Indeed, the vertical mass flux (e.g., omega at $500 \mathrm{hPa}$ ) decreases from the beginning of our simulations, which is consistent with the Held and Soden (2006) constraint (Fig. 10). This implies that during the transient response, the strengthening of the Walker circulation evident in surface and low-tropospheric variables (the SST and SLP gradients, and surface zonal winds) can be decoupled from the changes seen over the warm pool at $500 \mathrm{hPa}$.

The surface wind increase accompanying the weakening of the vertical velocity at $500 \mathrm{hPa}$ over the Indian and Pacific Oceans (Fig. 2d) may be possible because vertical velocity (Fig. 10) actually strengthens over the Maritime Continent. Thus, the surface manifestation of the weaker vertical velocity varies spatially due to land/ocean contrasts and contributes to the westward shift of the Walker circulation, rather than its slowdown. Eventually, at the equilibrium stage omega at $500 \mathrm{hPa}$ (Fig. 2d) shows a slowdown of $9 \%-35 \%$ across the warming scenarios. Compared with the average tropical warming from Fig. 7, which ranges from $1.4^{\circ}$ to $6^{\circ} \mathrm{C}$, this leads to a scaling of roughly $5 \%-6 \%$ per degree of warming, which appears to be consistent with the scaling of Held and Soden (2006). 

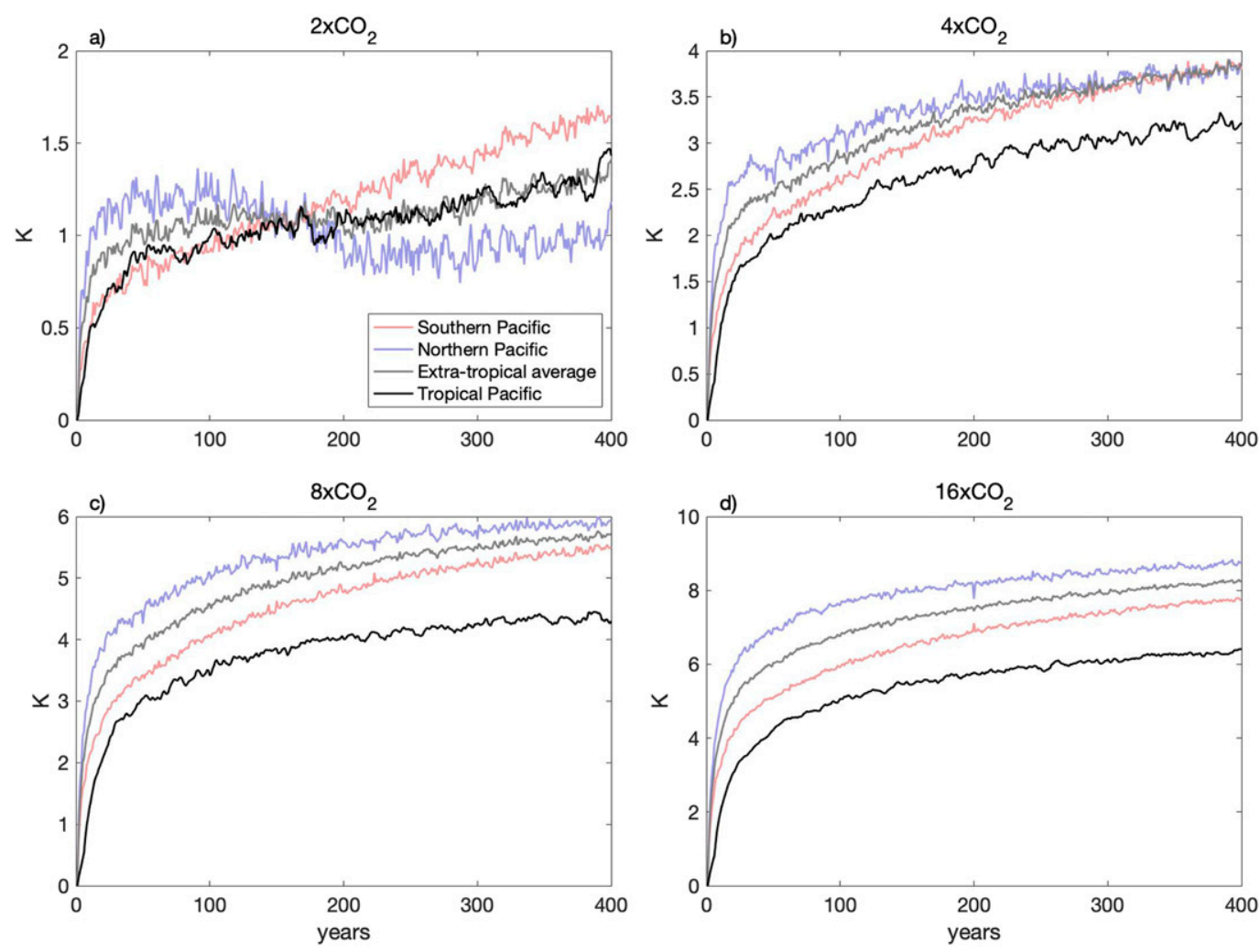

FIG. 7. SST changes in the tropical and extratropical Pacific for each $\mathrm{CO}_{2}$ scenario relative to the control. Lines represent ensemble means across five ensemble members. For the tropics, a 5-yr running average is applied.

\section{Idealized box model}

To further investigate the response of the tropical Pacific to $\mathrm{CO}_{2}$ forcing, an idealized box model is employed, which provides a simplified, theoretical basis for understanding the tropical Pacific SST response to greenhouse warming. The purpose of the box model is to isolate different mechanisms driving changes to the Pacific, while avoiding the spatially complex response observed in the GCM.

The simple model describes the wind-driven transport between the eastern and western equatorial Pacific, as well as between the equatorial Pacific and the extratropics, and thus is able to capture the main features of the ocean dynamical responses. Furthermore, it describes, in a simple form, atmosphere-ocean interaction via surface heat fluxes and wind coupling. It does not, however, incorporate the weakening of midtropospheric vertical velocity imposed by the energy/mass balance constraint.

\section{a. Model outline}

The model is modified from Liu and Huang (1997) (also see Burls and Fedorov 2014) and consists of four boxes (Fig. 11). The temperature change for each box is given by

$$
\begin{aligned}
m_{1} \frac{d T_{1}}{d t}= & m_{1} H_{1}+q(1-\varepsilon)\left(T_{2}-T_{1}\right), \\
m_{2} \frac{d T_{2}}{d t}= & m_{2} H_{2}+q\left(T_{4}-T_{2}\right), \\
m_{3} \frac{d T_{3}}{d t}= & m_{3} H_{3}+q \varepsilon\left(T_{2}-T_{3}\right) \\
& +q(1-\varepsilon)\left(T_{1}-T_{3}\right), \quad \text { and } \\
m_{4} \frac{d T_{4}}{d t}= & q\left(T_{3}-T_{4}\right),
\end{aligned}
$$

where $T_{i}$ is the temperature of box $i$, and $m_{i}$ is the volume of box $i$. The term $\varepsilon$ represents a branching parameter, which determines the ratio of water flowing out from the eastern and western tropical boxes, respectively. The term $H_{i}$ represents the temperature tendency for box $i$ induced by ocean-atmosphere heat fluxes, and is given by

$H_{i}=\frac{1}{C_{p} \rho h_{i}}\left[H_{\mathrm{sw}}-\left(H_{i_{\text {latent }}}+H_{\text {sensible }}+H_{i_{\mathrm{OLR}}}\right)\right], i=1,2,3$,

where $C_{p}$ is specific heat of water, $\rho$ is density of seawater, and $h_{i}$ is given by the depth of the mixed layer in 


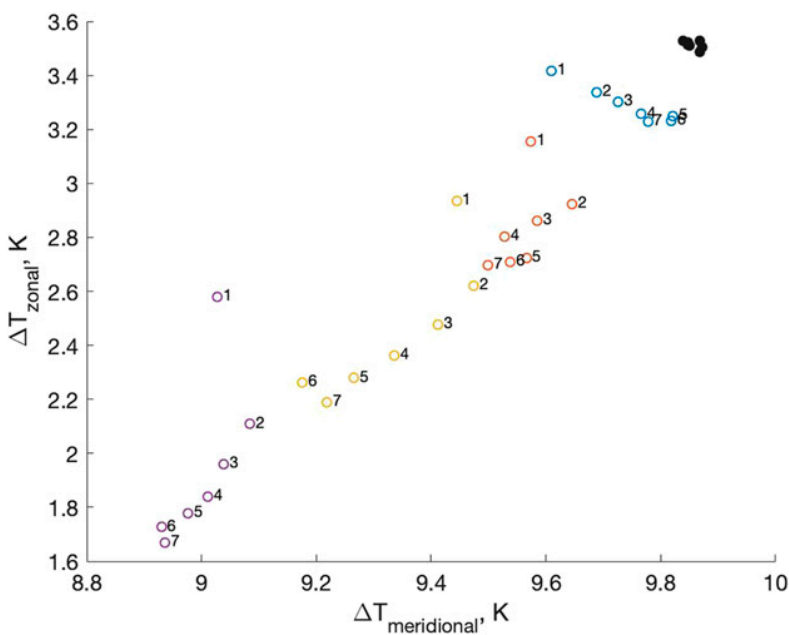

FIG. 8. Upper-ocean zonal temperature gradient plotted against the meridional upper-ocean temperature gradient in the Pacific (K). The vertical axis represents the upper 50-m ocean temperature between the west Pacific and the east Pacific. The horizontal axis represents the upper 50-m temperature difference between the tropical Pacific and the average between the northern and southern Pacific, as defined in Table 1. Each dot represents a 50-yr average of the simulation. Number 1 indicates an average for years 1-50, number 2 for years 51-100, etc. Each $\mathrm{CO}_{2}$ scenario is plotted with a different color, consistent with Fig. 6 . Black $=$ control simulation, blue $=2 \mathrm{xCO}_{2}$, red $=4 \mathrm{xCO}_{2}$, yellow $=8 \mathrm{xCO}_{2}$, and purple $=$ $16 \mathrm{xCO}_{2}$. Five-member ensemble means are used.

each box, and terms in the brackets on the rhs represent different components of surface heat fluxes. While the values of shortwave and sensible fluxes are prescribed for simplicity, based on average values in the GCM control run, the respective outgoing longwave (OLR) and latent heat fluxes are calculated, based on bulk formulas (e.g., Haney 1971):

$$
\begin{aligned}
& H_{i_{\mathrm{OLR}}}=E \sigma T_{i}^{4}, i=1,2,3, \\
& H_{i_{\text {Latent }}}=L V_{a_{i}} C_{L} \frac{0.622}{\rho_{\text {air }}} e_{s}\left(T_{i}\right)(1-\mathrm{RH}), i=1,2,3,
\end{aligned}
$$

where $E$ is an emissivity parameter, representing the efficiency at which the ocean surface cools via OLR, which in turn depends on clouds, water vapor, and other greenhouse gases in the atmosphere. This parameter is decreased to simulate warming caused by $\mathrm{CO}_{2}$ forcing. Also, $\sigma$ is the Stefan-Boltzmann constant, $\rho_{\text {air }}$ is the density of air at sea level, $C_{L}$ is the latent heat exchange coefficient, $V_{a}$ is the wind speed at $10 \mathrm{~m}, L$ is latent heat of evaporation, $e_{s}$ is saturation water vapor pressure, and $\mathrm{RH}$ is relative humidity of the surface boundary layer. Box 4 does not interact with the atmosphere and is assumed to be adiabatic, acting as a pipe, delaying the transport of temperature anomalies between the extratropical and tropical boxes.
Finally, the flow, $q$ is given by a simple parameterization:

$$
q=A_{H}\left(T_{\mathrm{eq}}-T_{3}\right)+A_{W}\left(T_{1}-T_{2}\right),
$$

where $A_{H}$ and $A_{W}$ represent the Hadley and Walker coupling parameters, respectively, and $T_{\text {eq }}$ is the average temperature of the tropical boxes (boxes 1 and 2). These are empirical coefficients linking the upper-ocean meridional and zonal temperature gradients to the resultant flow, via wind stress and Ekman transport. The values are obtained from the GCM simulations, with a partitioning following Liu and Huang (1997), where the Walker coupling is 4 times the Hadley coupling strength, and the resultant flow in a steady state is about $28 \mathrm{~Sv}$ $\left(1 \mathrm{~Sv} \equiv 10^{6} \mathrm{~m}^{3} \mathrm{~s}^{-1}\right)$, constrained by the upwelling into the eastern equatorial box (box 2) in the CESM control simulation (Burls and Fedorov 2014). The values for all variables and constants are given in Table 2.

We employ the model to study equilibrium and transient responses of the tropical SST gradient to several types of forcing:

1) Abrupt uniform reduction in the emissivity coefficient $E$ for all boxes (mimicking greenhouse warming)

2) Reduction in the emissivity coefficient for only box 3 (extratropical warming)

3) Abrupt uniform reduction in the emissivity coefficient for all boxes, with additional warming added to box 3 (global warming + enhanced extratropical warming)

4) Gradual uniform reduction in the emissivity coefficient for all boxes (gradual global warming)

Furthermore, we perform sensitivity tests in order to explore how the response of the model to warming depends on atmosphere-ocean coupling strength $\left(A_{H}\right.$ and $A_{W}$ parameters) and spatial variations in surface winds across the tropics. For the first sensitivity test, we alter the $A_{H}$ and $A_{W}$ parameters individually to explore how the model is behaving with different relative strengths between the Hadley and Walker couplings, and different flow rates. For the second test, we alter the surface wind speed $V_{a}$ to allow for different wind speeds between the eastern and western tropical boxes (box 1 and box 2).

\section{b. Box model results}

A clear transient strengthening of the east-west SST gradient is a robust feature of the box model when a uniform forcing is imposed (Fig. 12). The strengthening is generally stronger than the GCM results. Equilibrium SST gradient weakening is observed in the absence of enhanced extratropical warming (Fig. 12a), suggesting a 

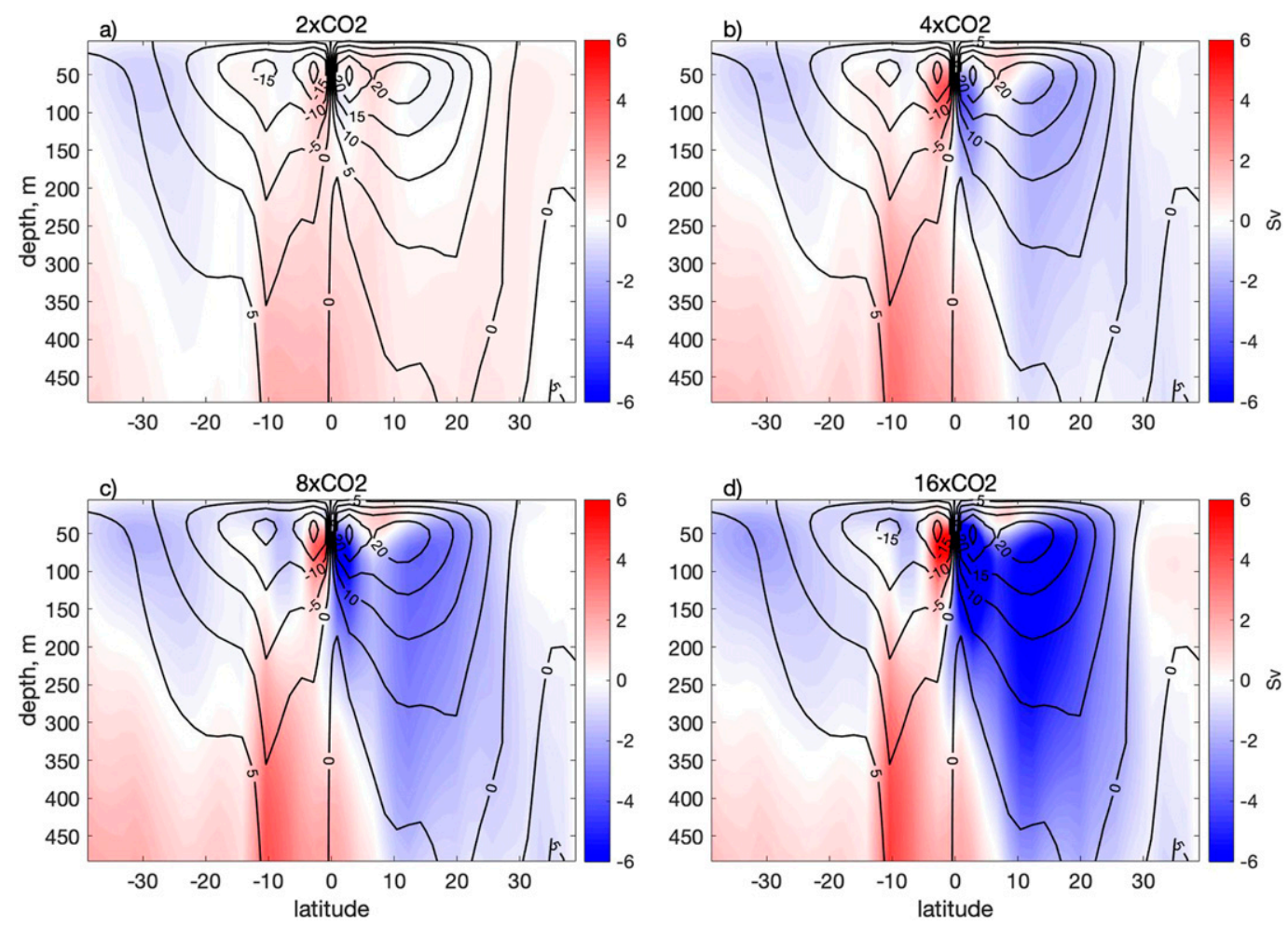

FIG. 9. Anomalies (colors) and the control mean values (contours) of the streamfunction (Sv) in the Pacific for each $\mathrm{CO}_{2}$ experiment based on a time average of 400 years. The plots show a substantial weakening of the upper 300-m meridional overturning within the northern subtropical cell (STC) while the southern cell becomes slightly stronger. The changes are minimal for $\mathrm{CO}_{2}$ doubling.

small, but not negligible role for the local, latent heat damping (evaporative damping) of the tropical SST gradient. If, however, an enhanced extratropical warming is imposed, the model shows a much more substantial weakening of the zonal SST gradient of magnitudes comparable to those in the fully coupled GCM experiments (Figs. 12b,c). This suggests that the oceanic tunnel may be important in driving the equilibrium response in the tropical Pacific: even in the absence of local effects, the zonal SST gradient can be substantially weakened if an extratropical warming is imposed (Fig. 12b).

Similarly, the gradual forcing experiment shows changes qualitatively similar to the ramped GCM experiments (Fig. 12d), highlighting that an ocean thermostat-type response may arise in both gradual and abrupt warming scenarios, however with a stronger magnitude in abrupt warming scenarios.

The sensitivity experiments shown in Figs. 13a and 13b suggest that the model tropical SST gradient is more sensitive to warming for low values of ocean-atmosphere coupling and flow rate when the model is in an undersaturated regime (Liu and Huang 1997). In such a regime, the effect of a positive pertubation to the flow rate would act to amplify small decreases in the SST gradient generated by differential changes in evaporative and OLR fluxes. An initial negative pertubation to the temperature gradient will in turn decrease upwelling into the eastern box (via $q$ ), which will act to decrease the east-west gradient (the Bjerknes feedback). If $q$ reaches a certain value, however, changes in the transport between eastern and western boxes dominate the east-west temperature gradient, and the system enters a saturated regime where decreased flow actually increases the gradient. Hence, if the model is close to saturation, the effect of warming on the tropical SST gradient greatly diminishes. This highlights the dependence of warming response on the ocean model's mean state circulation. For example, if a model overestimates eastern equatorial upwelling, it may in turn misrepresent the strength of the dynamical ocean response to warming because to model is too close to saturation.

Figures $13 \mathrm{c}$ and $13 \mathrm{~d}$ also shows the sensitivity of the box model to the value of tropical surface wind speed (which is held constant with time). While the model's response to warming is relatively insensitive to an increase or decrease of wind speed across the tropics, the model is sensitive to the relative difference in wind 

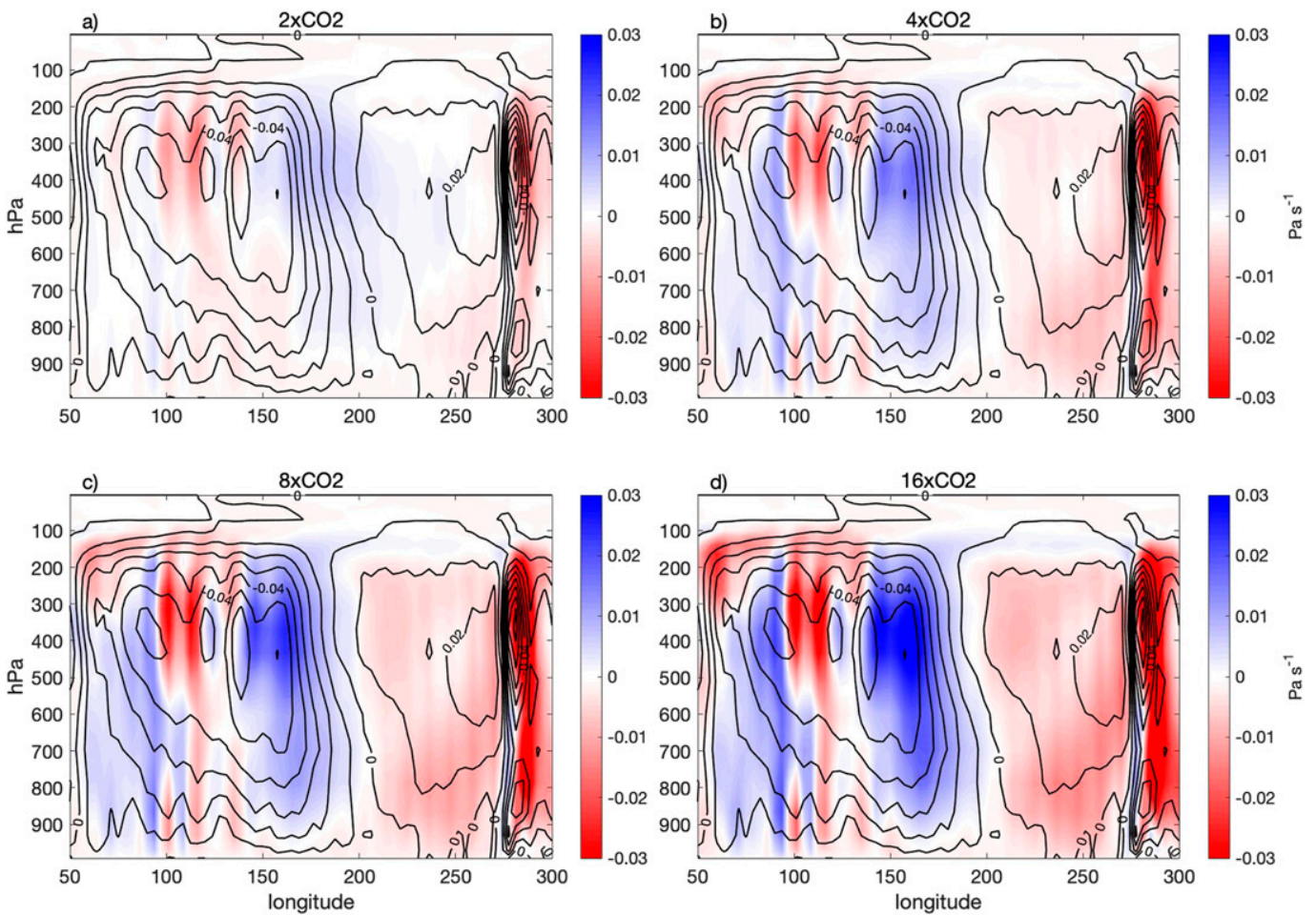

FIG. 10. Anomalies (colors) and the control mean values (contours) of ensemble-mean atmospheric vertical velocity $\omega\left(\mathrm{Pa} \mathrm{s}^{-1}\right)$ along the equator $\left(5^{\circ} \mathrm{S}-5^{\circ} \mathrm{N}\right)$ for the abrupt $\mathrm{CO}_{2}$ experiments averaged over the first 10 years of each simulation. Note that subsidence weakens in the eastern equatorial Pacific while convection strengthens over the Maritime Continent and adjacent regions of the Indo-Pacific warm pool, which effectively implies a westward shift of the Walker cell evident in the surface wind structure in Fig. 4.

magnitude between the eastern and western boxes. In fact, if mean winds are significantly stronger in the eastern box, relative to the western box, the equilibrium response to uniform warming is a strengthening of the SST gradient, rather than a weakening. This result highlights that the strength of the evaporative damping mechanism depends on the spatial pattern of mean state winds along the equator.

While the box model is too simple to be directly comparable to GCMs, it captures reasonably well the balance between different mechanisms that control tropical response to $\mathrm{CO}_{2}$ forcing, including dramatic differences between transient and equilibrium changes. Box model sensivitiy experiments thus show possible ways in which common GCM biases in the tropics, related to mean state winds and upper-ocean stratification (Li and Xie 2014), can affect the zonal tropical response to imposed radiative forcing by shifting this balance.

\section{Discussion and conclusions}

An initial strengthening of winds over the central equatorial Pacific, with an associated increase in
SST and SLP gradients, is a robust but transient response across all simulations with a dynamical ocean, indicating a dynamical Indo-Pacific Ocean thermostat mechanism at work. This strengthening lasts 20 years or so for the abrupt experiments, and 50-100 years for the gradual $\mathrm{CO}_{2}$ increase (ramped) experiments. The transient equatorial response is accompanied by increased vertical velocity and wind convergence over the Maritime Continent, decreased vertical velocity over the oceans, and a characteristic shift of the center of the warm pool toward the Indian Ocean. Our results suggest that the atmosphere plays an important role in setting this spatial shift, likely driven by land-sea differences in convection and temperature, and well as a Gill-type response to enhanced warming over the Indian Ocean (Matsuno 1966; Gill 1980). The box model simulations, however, confirm that it is possible to induce an ocean thermostat-like response as a result of an abrupt or gradual warming solely via Pacific coupled ocean-atmosphere dynamics. In other words, the role of the Indian Ocean and land-sea contrasts adds spatial complexity to a simple ocean thermostat response, which can be reproduced in an ocean box model coupled to a simple atmosphere. 


\section{Warm Pool}

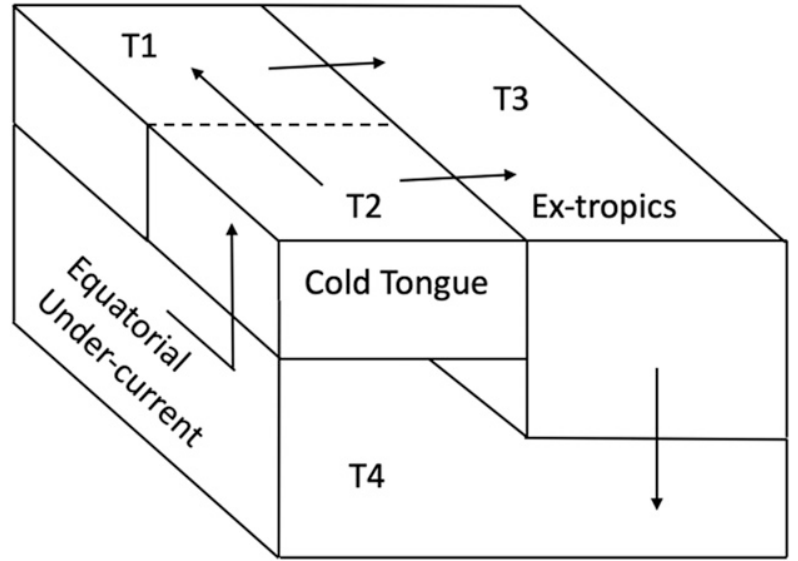

FIG. 11. A schematic outline of the four-box model. Water is upwelled into box 2 (the eastern tropical Pacific) and transported from there to box 1 (the western tropical Pacific) and box 3 (the extratropical Pacific). From there, water is subducted into the subsurface box (box 4), providing the link between the extratropical and equatorial boxes. The temperature in the surface boxes (boxes 1-3) is affected by longwave and shortwave and by latent and sensible heat exchanges with the atmosphere, while box 4 is assumed to be adiabatic.

The emergent, transient ocean thermostat-type response in GCMs and box models has also been reported by others (Luo et al. 2017; Ceppi et al. 2018; Liu 1998) in response to abrupt forcing. However, a notable new result here is that this transient response also features in gradual warming scenarios both in the GCM and the box model. The strongest response is obtained in the abrupt simulations, whereas the ramped simulations show a slightly muted and more slowly evolving response. Another new result is that the transient thermostat-like response occurs regardless the amplitude of $\mathrm{CO}_{2}$ increase. These findings illustrate the robust, yet transient nature of the ocean thermostattype response: once the extratropical oceans have adjusted to the warming, the stronger zonal SST gradient can no longer persist in the competition with other mechanisms that seek to weaken the zonal SST gradient (in particular if the upper-ocean warming is larger in the extratropics than the tropics).

Apparent similarities between this simulated transient response and the observed changes in the equatorial Pacific over the past decades are noticeable, highlighting the potential significance of the findings reported here. An increase in winds over the Pacific Ocean (McGregor et al. 2014), warming of the Indian Ocean (Luo et al. 2012; Lee et al. 2015), and westward shift of the Walker circulation (Ma and Zhou 2016) are all features of the recent trends in the region. Thus, whether a slowly evolving, transient response to
TABLE 2. Prescribed values and constants used for the box model experiments.

\begin{tabular}{|c|c|c|}
\hline Symbol & Value & Description \\
\hline$\varepsilon$ & 0.48 & $\begin{array}{l}\text { Ratio of flow out of eastern } \\
\text { (T2) vs western (T1) box }\end{array}$ \\
\hline$M_{1}$ & $6.8 \times 10^{6} \mathrm{~km}^{3}$ & Volume of box $\mathrm{T} 1$ \\
\hline$M_{2}$ & $6.8 \times 10^{5} \mathrm{~km}^{3}$ & Volume of box $\mathrm{T} 2$ \\
\hline$M_{3}$ & $5.2 \times 10^{6} \mathrm{~km}^{3}$ & Volume of box T3 \\
\hline$M_{4}$ & $5.2 \times 10^{6} \mathrm{~km}^{3}$ & Volume of box $\mathrm{T} 4$ \\
\hline$A_{W}$ & $10^{6} \mathrm{~m}^{3} \mathrm{~s}^{-1} \mathrm{~K}^{-1}$ & Walker coupling parameter \\
\hline$A_{H}$ & $4 \times 10^{6} \mathrm{~m}^{3} \mathrm{~s}^{-1} \mathrm{~K}^{-1}$ & Hadley coupling parameter \\
\hline$H_{1}$ & $50 \mathrm{~m}$ & Depth of box $\mathrm{T} 1$ \\
\hline $\mathrm{H}_{2}$ & $50 \mathrm{~m}$ & Depth of box T2 \\
\hline$H_{3}$ & $200 \mathrm{~m}$ & Depth of box T3 \\
\hline$C_{p}$ & $4.186 \mathrm{~J} \mathrm{~K}^{-1} \mathrm{~g}^{-1}$ & Specific heat of water \\
\hline$\rho$ & $10^{6} \mathrm{~g} \mathrm{~m}^{-3}$ & Density of water \\
\hline Sw & $240 \mathrm{~W} \mathrm{~m}^{-2}$ & $\begin{array}{l}\text { Prescribed shortwave forcing, } \\
\text { tropics }\end{array}$ \\
\hline $\mathrm{Sw}_{\mathrm{ex}}$ & $140 \mathrm{~W} \mathrm{~m}^{-2}$ & $\begin{array}{l}\text { Prescribed shortwave forcing, } \\
\text { extratropics }\end{array}$ \\
\hline$E$ & 0.18 & $\begin{array}{l}\text { Emissivity for control } \\
\text { experiment }\end{array}$ \\
\hline$\sigma$ & $5.67 \times 10^{-8} \mathrm{~W} \mathrm{~m}^{-2} \mathrm{~K}^{-4}$ & Stefan-Boltzmann constant \\
\hline$\rho_{\text {air }}$ & $1225 \mathrm{~g} \mathrm{~m}^{-3}$ & Density of air at sea level \\
\hline$V_{a_{\mathrm{T} 1}}$ & $5 \mathrm{~m} \mathrm{~s}^{-1}$ & $\begin{array}{l}\text { Tropical wind speed at } 10 \mathrm{~m} \text {, } \\
\text { box } \mathrm{T} 1\end{array}$ \\
\hline$V_{a_{\mathrm{T} 2}}$ & $5 \mathrm{~m} \mathrm{~s}^{-1}$ & $\begin{array}{l}\text { Tropical wind speed at } 10 \mathrm{~m} \text {, } \\
\text { box } \mathrm{T} 2\end{array}$ \\
\hline$V_{a_{\mathrm{et}}}$ & $8 \mathrm{~m} \mathrm{~s}^{-1}$ & $\begin{array}{l}\text { Extratropical wind speed at } \\
10 \mathrm{~m} \text {, box T3 }\end{array}$ \\
\hline$L_{d}$ & $1.5 \times 10^{-3}$ & Latent heat coefficient \\
\hline$L$ & $2260 \mathrm{~J} \mathrm{~g}^{-1}$ & Latent heat of evaporation \\
\hline RH & 0.8 & Relative humidity \\
\hline
\end{tabular}

anthropogenic warming is currently taking place should be subject to further investigation. Furthermore, based on the various time scales associated with the mechanisms illustrated in this study, the current response might not necessarily be permanent as suggested by Kohyama et al. (2017), but may be considered a transient response.

While the initial response is a strengthening of the Walker circulation, our model simulations indicate that in these experiments the oceanic tunnel is a key driver, setting the magnitude of the long-term weakening signal of the zonal SST gradient in the tropics. Enhanced extratropical oceanic warming is a prominent feature in this CESM model configuration, except for $2 \mathrm{xCO}_{2}$, which also shows the smallest degree of weakening in the SST gradient, and virtually no weakening in zonal wind stress along the equator in the equilibrium response. The warming of the extratropical ocean seems to be taking place alongside the weakening of the STCs, particularly in the Northern Hemisphere, suggesting that the response of equatorial SST is driven in part by extratropical warming, 

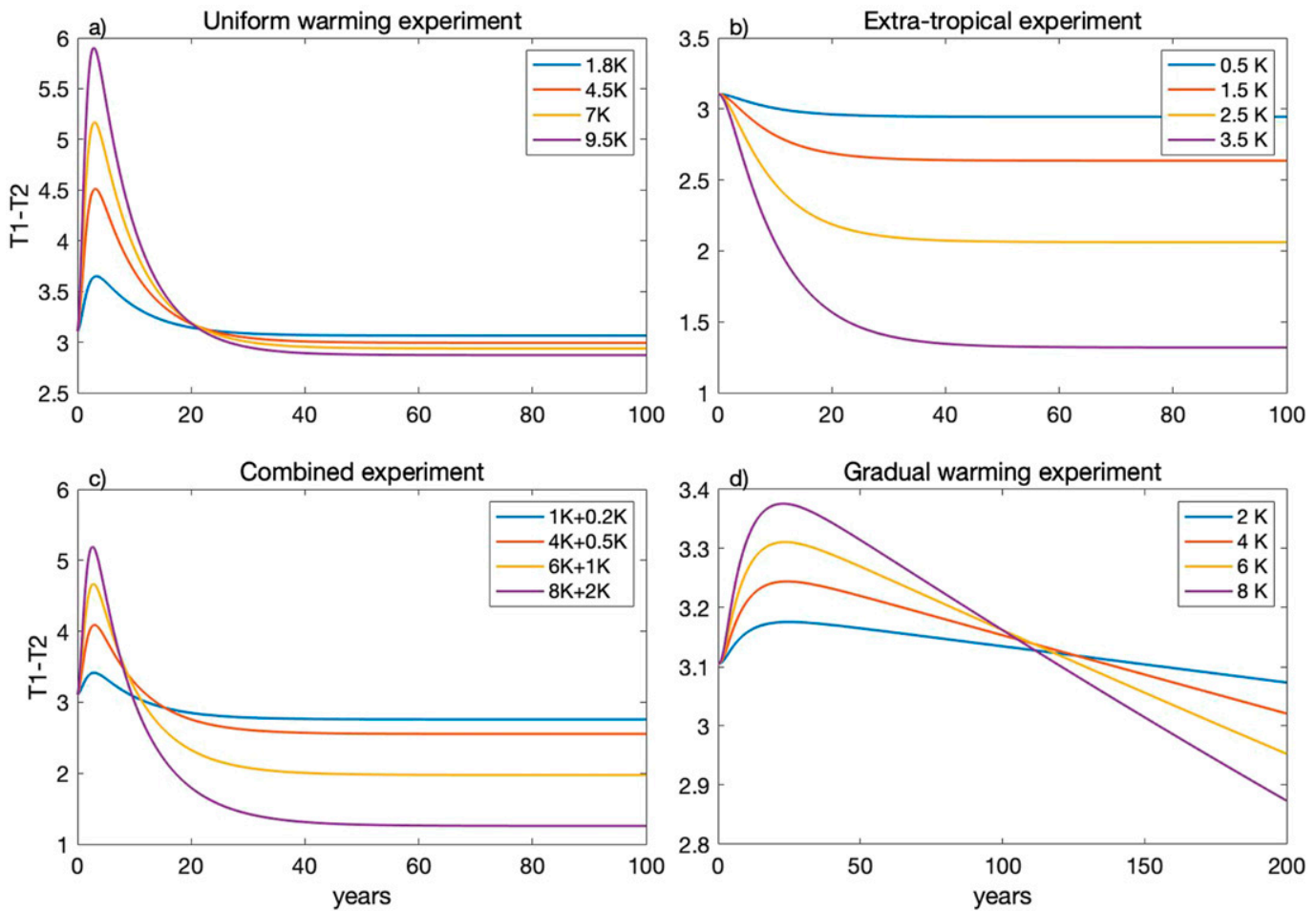

FIG. 12. Results of four different types of warming experiments conducted using the idealized box model described in the main text and Fig. 11. Changes in the tropical zonal upper-ocean temperature gradient (T1 - T2; K) are plotted for a range of warming magnitudes. (a) Uniform warming imposed abruptly in all three surface boxes by decreasing the OLR emissivity coefficient $E$ by $15 \%, 40 \%, 60 \%$, and $80 \%$. (b) Extratropical warming imposed by abruptly decreasing $E$ in the extratropical box by $5 \%, 10 \%, 20 \%$, and $30 \%$ with no imposed warming in the tropical boxes. (c) Abrupt warming with additional extratropical warming by decreasing $E$ in the tropical boxes by $10 \%$, $20 \%, 50 \%$ and $70 \%$, and in the extratropical box by $20 \%, 45 \%, 70 \%$, and $95 \%$. (d) Uniform warming is imposed gradually in all three surface boxes by decreasing $E$ linearly in time with the rate of $1.8 \times 10^{-4}, 3.6 \times 10^{-4}, 5.4 \times$ $10^{-4}$, and $7.2 \times 10^{-4} \mathrm{yr}^{-1}$. The resultant mean temperature change after 100 years is noted in the legend. In (c) both the mean tropical warming, and the additional extratropical warming are noted.

and in part by the weaker meridional flow with some hemispheric asymmetry.

The tight coupling between the tropical and extratropical warming, which is confirmed in our findings, raises an important question: If the meridional upperocean temperature gradients sets the magnitude of the equilibrium tropical zonal SST gradient, what, then, controls the magnitude of warming in the subtropical and midlatitude oceans? We speculate that the rate of extratropical warming may in large part be attributed to a competition between polar amplification (driven by cloud feedbacks and sea ice loss), and the rate of latent heat damping of warming, as suggested by Seager and Murtugudde (1997), which in turn may be linked to the structure and magnitude of mean winds and ocean stratification. The exact nature of the link between evaporative damping, polar amplification, subtropical ocean warming, and the model mean state winds and SST will be explored in a separate study. Preliminary results show that model simulations with similar physics, yet different horizontal resolution and mean state, can have markedly different rates of extratropical warming, and resultant differences in the tropical Pacific equilibrium response.

While our study is idealized, and the largest $\mathrm{CO}_{2}$ forcing in our simulations does not necessarily mimic the twenty-first-century climate change, the doubling and quadrupling of $\mathrm{CO}_{2}$ experiments are within feasible estimates for increases in atmospheric $\mathrm{CO}_{2}$ concentration for the coming centuries. More importantly, these simulations provide a useful framework for understanding the time scales and interaction between atmospheric and oceanic mechanisms driving changes to the tropical Pacific in response to $\mathrm{CO}_{2}$ forcing. By attributing the two responses (transient and equilibrium) to various atmospheric and oceanic mechanisms, our findings can be used to evaluate the large spread among CMIP model projections and the current discrepancies 

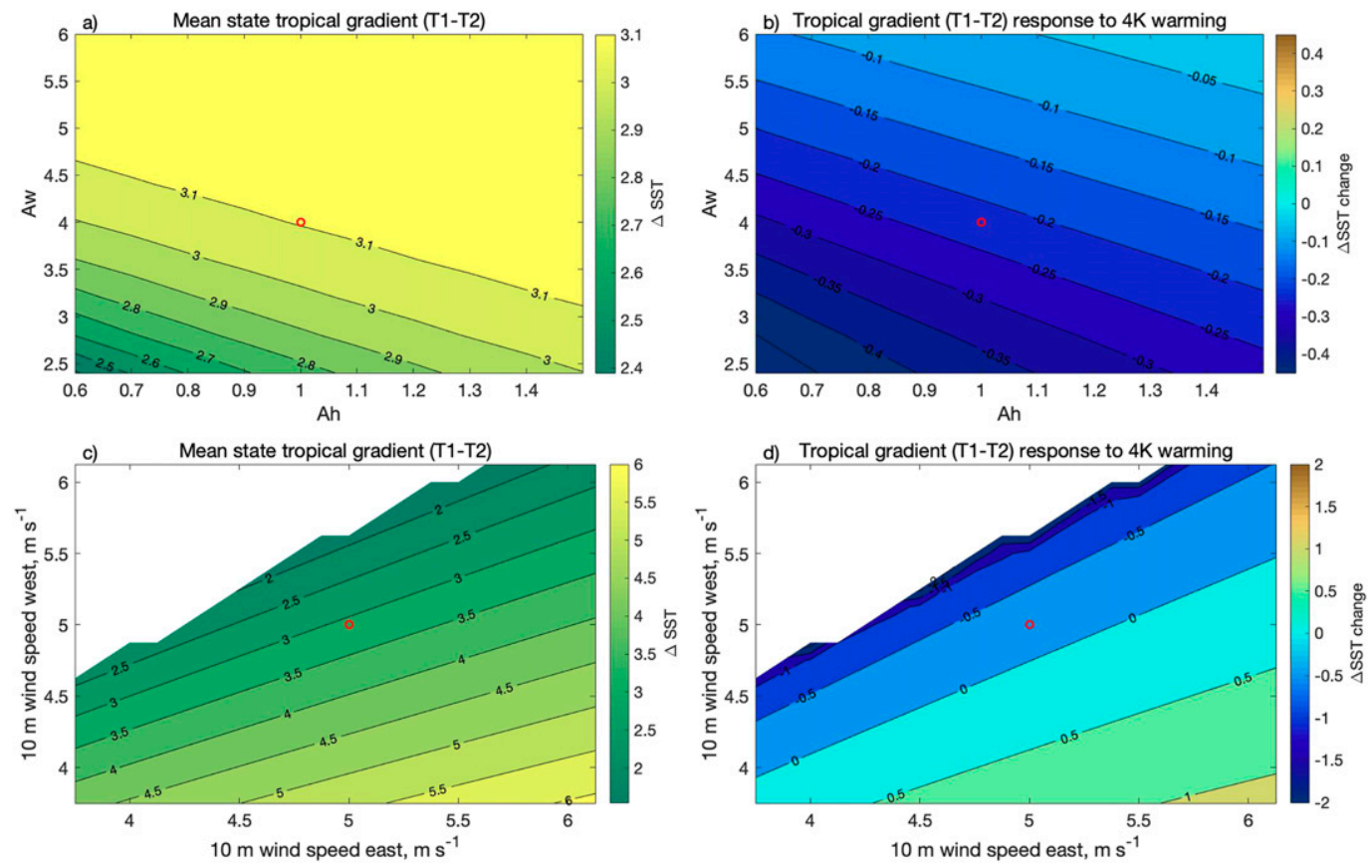

FIG. 13. The response of the idealized model to an imposed 4-K uniform warming for different values of (a),(b) the Walker and Hadley coupling parameters $\left(\mathrm{Sv} \mathrm{K}^{-1}\right)$ and (c),(d) the surface wind speed $\left(\mathrm{m} \mathrm{s}^{-1}\right)$ over the western and eastern equatorial boxes. (left) The mean state tropical upper-ocean temperature gradient (T1 - T2) and (right) the resultant equilibrium changes to the upper-ocean temperature gradient (K). Negative values indicate an upper-ocean temperature gradient reduction. The white areas are excluded from the analysis due to an unphysical mean state (a reverse temperature gradient between boxes $\mathrm{T} 1$ and $\mathrm{T} 2$ ). The red dot corresponds to values used in the experiments shown in Fig. 12.

between climate models simulations and the observational record. We have shown that there is an interplay between two types of responses, and the point at which they "switch" depends on the abruptness of the radiative forcing, the strength of the ocean thermostat, effectiveness of evaporative damping, tropical landatmosphere interaction, the extent of the warming of the extratropical oceans, and the weakening of the ocean subtropical cells. We find these factors to be the main contributors in driving large-scale changes in the equatorial Pacific mean state. As shown by previous studies, cloud feedbacks can modulate some of these factors (Erfani and Burls 2019) and additional processes might also influence the nature of the two responses, for example ENSO nonlinearity (Kohyama et al. 2018) and the dynamics of the equatorial undercurrent (Coats and Karnauskas 2018).

Furthermore, it is clear that persistent model biases (e.g., Li and Xie 2014; Burls et al. 2017; Li et al. 2016; Seager et al. 2019) can modify the climate system's response to warming. The large model spread in future projections changes for the tropical Pacific climate (i.e., Kociuba and Power 2015) represents a potential issue with our study, as we may expect other models to have different responses. For example, some models may exhibit different changes in meridional temperature gradients (caused by different cloud feedbacks, convection parameterizations or mean state circulation), leading to different ocean tunnel responses. In addition, models may have different sensitivities to the ocean thermostat type response due to different tropical Pacific mean state biases in ocean stratification, equatorial upwelling, and heat fluxes, as well as differences in landatmosphere interaction. Future research should therefore investigate how the balance between these transient and equilibrium responses manifests in other models, and how such differences can be related to various model biases. A study addressing some of these concerns is in preparation by the authors.

Acknowledgments. A.V.F. is supported by grants from the NSF (AGS-0163807) and NASA (NNX17AH21G), the ARCHANGE project of the "Make our planet great again" program (CNRS, France), and a Guggenheim fellowship. N.J.B. is supported by NSF AGS-1613318, AGS-1844380 and the Alfred P. Sloan Foundation as a Research Fellow. We would like to acknowledge high-performance computing support from Cheyenne 
(https://doi.org/10.5065/D6RX99HX) provided by NCAR's Computational and Information Systems Laboratory, sponsored by the NSF.

\section{REFERENCES}

Bjerknes, J., 1966: Survey of El Niño 1957-58 in its relation to tropical Pacific meteorology. Inter-Amer. Trop. Tuna Comm. Bull., 12, 1-62.

Burls, N. J., and A. V. Fedorov, 2014: What controls the mean eastwest sea surface temperature gradient in the equatorial Pacific: The role of cloud albedo. J. Climate, 27, 2757-2778, https://doi.org/10.1175/JCLI-D-13-00255.1.

_ L. Muir, E. M. Vincent, and A. Fedorov, 2017: Extra-tropical origin of equatorial Pacific cold bias in climate models with links to cloud albedo. Climate Dyn., 49, 2093-2113, https:// doi.org/10.1007/s00382-016-3435-6.

Ceppi, P., G. Zappa, T. G. Shepherd, and J. M. Gregory, 2018: Fast and slow components of the extratropical atmospheric circulation response to $\mathrm{CO}_{2}$ forcing. J. Climate, 31, 1091-1105, https://doi.org/10.1175/JCLI-D-17-0323.1.

Chadwick, R., I. Boutle, and G. Martin, 2013: Spatial patterns of precipitation change in CMIP5: Why the rich do not get richer in the tropics. J. Climate, 26, 3803-3822, https://doi.org/ 10.1175/JCLI-D-12-00543.1.

Chiang, J. C., and D. J. Vimont, 2004: Analogous Pacific and Atlantic meridional modes of tropical atmosphere-ocean variability. J. Climate, 17, 4143-4158, https://doi.org/10.1175/ JCLI4953.1.

Clement, A. C., R. Seager, M. A. Cane, and S. E. Zebiak, 1996: An ocean dynamical thermostat. J. Climate, 9, 2190-2196, https:// doi.org/10.1175/1520-0442(1996)009<2190:AODT>2.0.CO;2.

Coats, S., and K. B. Karnauskas, 2017: Are simulated and observed twentieth century tropical Pacific sea surface temperature trends significant relative to internal variability? Geophys. Res. Lett., 44, 9928-9937, https://doi.org/10.1002/ 2017 GL074622.

—- and - 2018: A role for the Equatorial Undercurrent in the ocean dynamical thermostat. J. Climate, 31, 6245-6261, https:// doi.org/10.1175/JCLI-D-17-0513.1.

Collins, M., and Coauthors, 2010: The impact of global warming on the tropical Pacific Ocean and El Niño. Nat. Geosci., 3, 391397, https://doi.org/10.1038/ngeo868.

Dayem, K. E., D. C. Noone, and P. Molnar, 2007: Tropical western Pacific warm pool and Maritime Continent precipitation rates and their contrasting relationships with the Walker circulation. J. Geophys. Res., 112, D06101, https://doi.org/10.1029/ 2006JD007870.

DiNezio, P. N., A. C. Clement, G. A. Vecchi, B. J. Soden, B. P. Kirtman, and S.-K. Lee, 2009: Climate response of the equatorial Pacific to global warming. J. Climate, 22, 4873-4892, https://doi.org/10.1175/2009JCLI2982.1.

_ B. P. Kirtman, A. C. Clement, S.-K. Lee, G. A. Vecchi, and A. Wittenberg, 2012: Mean climate controls on the simulated response of ENSO to increasing greenhouse gases. J. Climate, 25, 7399-7420, https://doi.org/10.1175/JCLI-D-11-00494.1.

_ G. A. Vecchi, and A. C. Clement, 2013: Detectability of changes in the Walker circulation in response to global warming. J. Climate, 26, 4038-4048, https://doi.org/10.1175/ JCLI-D-12-00531.1.

Dong, B., and A. Dai, 2015: The influence of the interdecadal Pacific oscillation on temperature and precipitation over the globe. Climate Dyn., 45, 2667-2681, https://doi.org/10.1007/ s00382-015-2500-x.

England, M. H., and Coauthors, 2014: Recent intensification of wind-driven circulation in the Pacific and the ongoing warming hiatus. Nat. Climate Change, 4, 222-227, https://doi.org/ 10.1038/nclimate2106.

Erfani, E., and N. J. Burls, 2019: The strength of low-cloud feedbacks and tropical climate: A CESM sensitivity study. J. Climate, 32, 2497-2516, https://doi.org/10.1175/JCLI-D18-0551.1.

Fedorov, A. V., and S. G. Philander, 2000: Is El Niño changing? Science, 288, 1997-2002, https://doi.org/10.1126/science.288.5473.1997.

_ N. J. Burls, K. T. Lawrence, and L. C. Peterson, 2015: Tightly linked zonal and meridional sea surface temperature gradients over the past five million years. Nat. Geosci., 8, 975-980, https://doi.org/10.1038/ngeo2577.

Gill, A. E., 1980: Some simple solutions for heat-induced tropical circulation. Quart. J. Roy. Meteor. Soc., 106, 447-462, https:// doi.org/10.1002/qj.49710644905.

Gu, D., and S. G. Philander, 1997: Interdecadal climate fluctuations that depend on exchanges between the tropics and extratropics. Science, 275, 805-807, https://doi.org/10.1126/ science.275.5301.805.

Haney, R. L., 1971: Surface thermal boundary condition for ocean circulation models. J. Phys. Oceanogr., 1, 241-248, https:// doi.org/10.1175/1520-0485(1971)001<0241:STBCFO > 2.0.CO;2.

Held, I. M., and B. J. Soden, 2006: Robust responses of the hydrological cycle to global warming. J. Climate, 19, 5686-5699, https://doi.org/10.1175/JCLI3990.1.

$\mathrm{Hu}, \mathrm{S}$., and A. V. Fedorov, 2018: Cross-equatorial winds control El Niño diversity and change. Nat. Climate Change, 8, 798-802, https://doi.org/10.1038/s41558-018-0248-0.

— , and 2019: Indian Ocean warming can strenthen the Atlantic meridional overturning circulation. Nat. Climate Change, 9, 747-751, https://doi.org/10.1038/s41558-019-0566-x.

Kay, J. E., and Coauthors, 2015: The Community Earth System Model (CESM) large ensemble project: A community resource for studying climate change in the presence of internal climate variability. Bull. Amer. Meteor. Soc., 96, 1333-1349, https://doi.org/10.1175/BAMS-D-13-00255.1.

Knutson, T. R., and S. Manabe, 1995: Time-mean response over the tropical Pacific to increased $\mathrm{CO}_{2}$ in a coupled oceanatmosphere model. J. Climate, $\mathbf{8}, 2181-2199$, https://doi.org/ 10.1175/1520-0442(1995)008<2181:TMROTT >2.0.CO;2.

Kociuba, G., and S. B. Power, 2015: Inability of CMIP5 models to simulate recent strengthening of the Walker circulation: Implications for projections. J. Climate, 28, 20-35, https:// doi.org/10.1175/JCLI-D-13-00752.1.

Kohyama, T., D. L. Hartmann, and D. S. Battisti, 2017: La Niñalike mean-state response to global warming and potential oceanic roles. J. Climate, 30, 4207-4225, https://doi.org/10.1175/ JCLI-D-16-0441.1.

,-- , and 2018: Weakening of nonlinear ENSO under global warming. Geophys. Res. Lett., 45, 8557-8567, https:// doi.org/10.1029/2018GL079085.

Krishnamurthy, L., and V. Krishnamurthy, 2014: Influence of PDO on South Asian summer monsoon and monsoon-ENSO relation. Climate Dyn., 42, 2397-2410, https://doi.org/10.1007/ s00382-013-1856-z.

Lee, S.-K., W. Park, M. O. Baringer, A. L. Gordon, B. Huber, and Y. Liu, 2015: Pacific origin of the abrupt increase in Indian Ocean heat content during the warming hiatus. Nat. Geosci., 8, 445-449, https://doi.org/10.1038/ngeo2438. 
Li, G., and S.-P. Xie, 2014: Tropical biases in CMIP5 multimodel ensemble: The excessive equatorial Pacific cold tongue and double ITCZ problems. J. Climate, 27, 1765-1780, https:// doi.org/10.1175/JCLI-D-13-00337.1.

,,-- Y. Du, and Y. Luo, 2016: Effects of excessive equatorial cold tongue bias on the projections of tropical Pacific climate change. Part I: The warming pattern in CMIP5 multi-model ensemble. Climate Dyn., 47, 3817-3831, https://doi.org/10.1007/ s00382-016-3043-5.

Liu, Z., 1998: The role of ocean in the response of tropical climatology to global warming: The west-east SST contrast. J. Climate, 11, 864-875, https://doi.org/10.1175/1520-0442(1998)011<0864: TROOIT $>2.0 . \mathrm{CO} ; 2$.

, and B. Huang, 1997: A coupled theory of tropical climatology: Warm pool, cold tongue, and Walker circulation. J. Climate, 10, 1662-1679, https://doi.org/10.1175/1520-0442(1997)010<1662: ACTOTC $>2.0 . \mathrm{CO} ; 2$.

Luo, J.-J., W. Sasaki, and Y. Masumoto, 2012: Indian Ocean warming modulates Pacific climate change. Proc. Natl. Acad. Sci. USA, 109, 18 701-18706, https://doi.org/10.1073/ pnas.1210239109.

Luo, Y., J. Lu, F. Liu, and W. Liu, 2015: Understanding the El Niño-like oceanic response in the tropical Pacific to global warming. Climate Dyn., 45, 1945-1964, https://doi.org/10.1007/ s00382-014-2448-2.

,,--- , and O. Garuba, 2017: The role of ocean dynamical thermostat in delaying the El Niño-like response over the equatorial Pacific to climate warming. J. Climate, 30, 28112827, https://doi.org/10.1175/JCLI-D-16-0454.1.

Ma, S., and T. Zhou, 2016: Robust strengthening and westward shift of the tropical Pacific Walker circulation during 19792012: A comparison of 7 sets of reanalysis data and 26 CMIP5 models. J. Climate, 29, 3097-3118, https://doi.org/10.1175/ JCLI-D-15-0398.1.

Matsuno, T., 1966: Quasi-geostrophic motions in the equatorial area. J. Meteor. Soc. Japan, 44, 25-43, https://doi.org/10.2151/ jmsj1965.44.1_25.

McCreary, J. P., Jr., and P. Lu, 1994: Interaction between the subtropical and equatorial ocean circulations: The subtropical cell. J. Phys. Oceanogr., 24, 466-497, https://doi.org/10.1175/ 1520-0485(1994)024<0466:IBTSAE > 2.0.CO;2.

McGregor, S., A. Timmermann, M. F. Stuecker, M. H. England, M. Merrifield, F.-F. Jin, and Y. Chikamoto, 2014: Recent Walker circulation strengthening and Pacific cooling amplified by Atlantic warming. Nat. Climate Change, 4, 888-892, https:// doi.org/10.1038/nclimate2330.

Meng, Q., M. Latif, W. Park, N. S. Keenlyside, V. A. Semenov, and T. Martin, 2012: Twentieth century Walker circulation change: Data analysis and model experiments. Climate Dyn., 38, 17571773, https://doi.org/10.1007/s00382-011-1047-8.

Merlis, T. M., and T. Schneider, 2011: Changes in zonal surface temperature gradients and Walker circulations in a wide range of climates. J. Climate, 24, 4757-4768, https://doi.org/10.1175/ 2011JCLI4042.1.
Plesca, E., V. Grützun, and S. A. Buehler, 2018: How robust is the weakening of the Pacific Walker circulation in CMIP5 idealized transient climate simulations? J. Climate, 31, 81-97, https://doi.org/10.1175/JCLI-D-17-0151.1.

Rodgers, K. B., B. Blanke, G. Madec, O. Aumont, P. Ciais, and J.-C. Dutay, 2003: Extratropical sources of equatorial Pacific upwelling in an OGCM. Geophys. Res. Lett., 30, 1080, https:// doi.org/10.1029/2002GL016003.

Seager, R., and R. Murtugudde, 1997: Ocean dynamics, thermocline adjustment, and regulation of tropical SST. J. Climate, 10, 521-534, https://doi.org/10.1175/1520-0442(1997)010<0521: ODTAAR $>2.0 . \mathrm{CO} ; 2$.

—, M. Cane, N. Henderson, D.-E. Lee, R. Abernathey, and H. Zhang, 2019: Strengthening tropical Pacific zonal sea surface temperature gradient consistent with rising greenhouse gases. Nat. Climate Change, 9, 517-522, https://doi.org/10.1038/ s41558-019-0505-x.

Thomas, M. D., and A. V. Fedorov, 2017: The eastern subtropical Pacific origin of the equatorial cold bias in climate models: A Lagrangian perspective. J. Climate, 30, 5885-5900, https:// doi.org/10.1175/JCLI-D-16-0819.1.

Tokinaga, H., S.-P. Xie, A. Timmermann, S. McGregor, T. Ogata, H. Kubota, and Y. M. Okumura, 2012: Regional patterns of tropical Indo-Pacific climate change: Evidence of the Walker circulation weakening. J. Climate, 25, 1689-1710, https:// doi.org/10.1175/JCLI-D-11-00263.1.

Vecchi, G. A., and B. J. Soden, 2007: Global warming and the weakening of the tropical circulation. J. Climate, 20, 43164340, https://doi.org/10.1175/JCLI4258.1.

Xie, S.-P., and S. G. H. Philander, 1994: A coupled ocean-atmosphere model of relevance to the ITCZ in the eastern Pacific. Tellus., 46A, 340-350, https://doi.org/10.3402/tellusa.v46i4.15484.

Yamanaka, G., H. Tsujino, H. Nakano, and M. Hirabara, 2015: Decadal variability of the Pacific subtropical cells and its relevance to the sea surface height in the western tropical Pacific during recent decades. J. Geophys. Res. Oceans, 120, 201-224, https://doi.org/10.1002/2014JC010190.

Zhang, H., C. Deser, A. Clement, and R. Tomas, 2014: Equatorial signatures of the Pacific meridional modes: Dependence on mean climate state. Geophys. Res. Lett., 41, 568-574, https:// doi.org/10.1002/2013GL058842.

Zhang, L., and K. B. Karnauskas, 2017: The role of tropical interbasin SST gradients in forcing Walker circulation trends. J. Climate, 30, 499-508, https://doi.org/10.1175/JCLI-D-160349.1.

— W. Han, K. B. Karnauskas, G. A. Meehl, A. Hu, N. Rosenbloom, and T. Shinoda, 2019: Indian Ocean warming trend reduces Pacific warming response to anthropogenic greenhouse gases: An interbasin thermostat mechanism. Geophys. Res. Lett., 46, 10 882-10 890, https://doi.org/10.1029/2019GL084088.

Zhao, B., and A. Fedorov, 2020: The effects of background zonal and meridional winds on ENSO in a coupled GCM. J. Climate, 33, 2075-2091, https://doi.org/10.1175/JCLI-D-18-0822.1. 